\title{
Entropy Analysis and Thermal Characteristics of Reiner Philippoff Hybrid Nanofluidic Flow Via a Parabolic Trough of Solar Aircraft Wings: Keller Box Method
}

\section{Tanveer Sajid}

Capital University of Science and Technology (CUST)

Wasim Jamshed

Capital University of Science and Technology (CUST)

Faisal Shahzad

Capital University of Science and Technology (CUST)

Mohamed R. Eid

New Valley University

Esra Karataş Akgül ( $\square$ esrakaratas@siirt.edu.tr)

Siirt University

Kottakkaran Sooppy Nisar

Prince Sattam bin Abdulaziz University

\section{Research Article}

Keywords: Solar Aircraft, PTSC, Thermal radiation, Heat generation

Posted Date: August 4th, 2021

DOI: https://doi.org/10.21203/rs.3.rs-763495/v1

License: (c) (1) This work is licensed under a Creative Commons Attribution 4.0 International License.

Read Full License 


\title{
Entropy Analysis and Thermal Characteristics of Reiner Philippoff Hybrid Nanofluidic Flow Via a Parabolic Trough of Solar Aircraft Wings: Keller Box Method
}

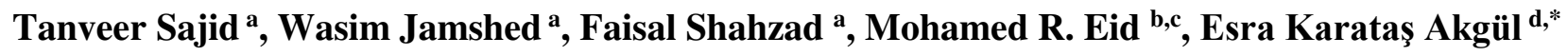 \\ and Kottakkaran Sooppy Nisar ${ }^{\mathrm{e}}$ \\ ${ }^{a}$ Department of Mathematics, Capital University of Science and Technology (CUST), Islamabad, 44000, Pakistan. \\ ${ }^{\mathrm{b}}$ Department of Mathematics, Faculty of Science, New Valley University, Al-Kharga, Al-Wadi Al-Gadid, 72511 Egypt. \\ ${ }^{c}$ Department of Mathematics, Faculty of Science, Northern Border University, Arar, 1321, Saudi Arabia. \\ ${ }^{\mathrm{d}}$ Art and Science Faculty, Department of Mathematics, Siirt University, TR-56100, Siirt, Turkey. \\ e Department of Mathematics, Prince Sattam bin Abdulaziz University, Wadi Aldawaser, 11991, Saudi Arabia. \\ *Corresponding Author, E. K. Akgül (esrakaratas@siirt.edu.tr)
}

\begin{abstract}
Solar energy is about the study of solar radiations and a method to enhance the efficacy of solar aircrafts with the utilization of solar radiations and nanotechnology. Solar radiations has been considered a heat source. The heat transmission performance of the wings is scrutinized for the situation of various effects like thermal radiations, heat generation, variant thermal conductance, thermal conductivity, and viscidness dissipative flow. Entropy generation analysis has been carried out in the status of Reiner Philippoff nanofluid (RPNF). The performance of the solar aircraft wings (SACW) improves in relations of thermal transmission for the status of amplification in thermal radiation, heat generation, viscidness dissipative flowing, and thermal conductivity parameters.
\end{abstract}

Keywords: Solar Aircraft, PTSC, Thermal radiation, Heat generation.

\section{Introduction}

In agricultural ecosystems, ground solar energy improvements are growing due to the situation of utility-scale improvements of solar energy in previous agricultural areas. A sun always divides water, allows it to evaporate sun heat, cool it off, and then collect water. They are used in areas where there is no drinking water. The clean water is then obtained by showing it in sunlight from polluted water or plants. Many solar organisms also produce big condensed sunscreens and condensation traps. Unclean water is still present in a solar system outside the collector and is 
vaporized by transparent plastic or crystal clear sunlight. Solar energy is assisted by the most advantageous green technologies. These systems, however, are heavily climate-dependent creating time gaps between the availability of resources and energy use. In certain implementations such as desalination of salt-water, waste sterilization, and electricity generation, solar energy can be used to constitute steam [1,2]. Nanotechnology has helped to achieve valuable improvement in these systems' efficiency [3]. The use of appropriate nanofluids would provide useful improvements to the precise operation of these devices. Applying the gold particles to plasmonic nanofluids will increase the precision of the systems by around 300. In solar steam generation systems, Nanofluids with CNTs are the appropriate choices. In a solar direct vapor environment, Wang et al. [4] have applied the SWCNT nanofluid and investigated the impacts of solar energy density and nanofluid levels. They also accomplished that the rate of evaporation has improved by increasing the amount of nanofluid and solar power.

Solar aircraft have a continuous cruise ability of 24 hours and are more visible, less flying speed, and less structural than conventional aircraft. Improvements in aerodynamic characteristics and appropriate structural weight reductions are the main factors in continuous solar aircraft cruising. Solar aircraft have special construction methods, conventional aircraft configuration features and the wings used in solar aircraft are extremely different [5]. Solar energy has a widespread appeal as an environmentally friendly, affordable, and inexhaustible alternative. Parabolic solar technology is the furthermost developed and cost-efficient, highly effective solar energy technology in existence today among three fundamental solar thermal generating systems comprising the parabolic trough, the central receptor, and the parabolic dish [6]. Cost is, however, a key factor restricting the improvement of the PTC scheme. This problem will in part be alleviated by developing the thermal operation of the PTC method. Nanofluid has demonstrated a decent capacity to improve solar systems performance.

This specific liquid has been predicted as a topic of intensive global research by the extraordinary thermo and flow properties of nanofluid in comparison to traditional thermo transportation media. These powerful nanofluids work well with improved thermal conductance in lower concentrations of nanoparticles. It is also helpful in biomedical processing, soldering, lubrication, power systems, satellites, aeronautical devices, and thermal coordination for vehicles. Many authors are widely engaged in the application of nanomaterials to increase heat transfer. Conventional heat transfer rates cannot be obtained due to their inherently poor thermal conductance 
under improved heat flux conditions. Over the last decade, the new approach of optimizing heat transfer by the application of ultrafine rigid particles in fluids has been widely explored. Choi [7] also introduced the term nanofluid to evaluate the thermal suspension in the base fluid with a higher precision through the dissemination of such nanosized solid particles. Early researches of nanofluids with a diversity of base fluids (propylene glycol (PG), $\mathrm{H}_{2} \mathrm{O}$, oils, etc.), calculated viscidness, thermal conductance, and observed that these nanofluid attributes were improved concerning the based fluids [8-12]. Apart from the thermal conductance and viscidness, the electric conductance of nano-solid particles ( $\mathrm{Cu}, \mathrm{Ag}, \mathrm{Au}, \mathrm{CuO}, \mathrm{ZnO}, \mathrm{SiO}_{2}, \mathrm{Fe}_{3} \mathrm{O}_{4}, \mathrm{Al}_{2} \mathrm{O}_{3}, \mathrm{TiO}_{2}, \mathrm{CNT}$, etc.) and spread over many based liquids $\left(\mathrm{H}_{2} \mathrm{O}, \mathrm{PG}\right.$, Palm Oil, Coconut Oil, etc. $)$ has been investigated for varying temperature ranges at different fractional sizes of these particles [13-15].

There has been a wide variety of research into modern nanofluid production; such liquids are referred to as hybrid nanofluid (HNF). Because of the combined impact of the interaction of multiple materials, HNFs boost their thermal properties. Jana and colleagues [16] first studied the hybridisation of various forms of nanoparticles to produce HNFs. The concept was to increase HNF thermal conductance over traditional nanofluids. This latest improvement is a conventional issue among researchers due to its possible benefits to nanofluids, results in the existence of several nanomolecules in the working liquid [17]. Many researchers have presumed that hybrid nanofluids or fused, mixed, or combined with two types of nanoparticles are present [18]. The concept to use HNFs is also to increase thermo-physical features, particularly the heat switch charge compared to regular nanofluids. Although the current type of nanoliquids is HNFs, their evaluation process is still in the improvement phase. High efficiency in terms of heat transfer can be expected by using HNFs [19]. Some nano-solid particles, including metal particles ( $\mathrm{Au}, \mathrm{Al}, \mathrm{Ag}, \mathrm{Cu}$, and Fe), CNTs, and metallic oxides $\left(\mathrm{Al}_{2} \mathrm{O}_{3}, \mathrm{TiO}_{2}, \mathrm{CuO}, \mathrm{SiC}\right.$, and $\left.\mathrm{Fe}_{3} \mathrm{O}_{4}\right)$, were fascinated by the extensive groups of nanofluids [20]. Nanofluids offer unusual rheological results and thermo-physicochemical properties in different unit HNFs. Appropriate and satisfactory stability of the HNFs were appeared [21].

The use of renewable energy is a mechanism for overcoming the global energy crisis and plays a vital part in protecting the atmosphere against waste and emissions of all kinds of gases. Solar energy is also an integral basis of energy since the question is broadly posed to increase the accuracy of manufacturing technologies to improve organizational and environmental energy management $[22,23]$. Linear Fresnel-reflectors (LFRs) are between the solar-collectors utilized for thermal converting solar-energy. Many works show that LFRs are an alternative approach that meets existing 
energy needs [24-26]. Because of the poor thermal efficacy of the LFR, HNFs are a potential alternative for increasing the heat accuracy of the sample fluid by improving the thermal transfer functionality [27-34].

Entropy analysis is a valuable method to optimize thermal systems efficiency. The adding of nanomolecules to the standard liquid is known to affect the overall entropy generation. The use of nanofluids in thermal systems lowers the system temperature and ultimately reduces the contribution of the heat transfer to overall entropy production, thus added nanoparticles in the normal liquid upsurge the viscidness of the operating liquid leading to a reduction in the structure strain. Lots of studies have been studying entropy production to get optimal constraints for various thermally models and this is only covered by several articles. Sciacovelli et al. [35] for example, examined contributions to entropy-generation research theory and application to various systems of engineering. The second law analysis used for heater exchangers was used to interpret the examination of Manjunath and Kaushik [36]. Later on, Torabi et al. [37] were up-to-date in porous models for entropy production. In mono/hybrid nanofluids flow entropy production only an evaluation has been conducted in [38]. This evaluation includes an exhaustive study on entropy production in various geometries and flowing regimes

Solar radiations has been considered a heat source. The thermal transmission efficacy of the wings is analyzed for the status of diverse influences like thermal radiative flowing, heat generation, variant thermal conductance, and viscous dissipative flowing. Entropy production scrutiny has been carried out in the situation of RPNF. The modeled equations in terms of momentum and energy have been handled by Keller box technique (KBT). The effect of various potential factors on flow speed,

shear-stress, and energy fields over and above frictional force coefficient and Nusselt number are discussed briefly and displayed in terms of figures and tables.

\section{Model Formulations}

The relationship of RPNF stress deformation [39] is presented as:

$$
\frac{\partial u}{\partial y}=\frac{\tau}{\mu_{\infty}+\frac{\mu_{0}-\mu_{\infty}}{1+\left(\frac{\tau}{\tau_{S}}\right)^{2}} .}
$$

We consider

$$
f(\sigma)=\frac{\sigma}{1+\frac{\lambda-1}{1+\sigma^{2}}}
$$


where $\sigma=\frac{\tau}{\tau_{s}}$ and $\lambda=\frac{\mu_{0}}{\mu_{\infty}}$.

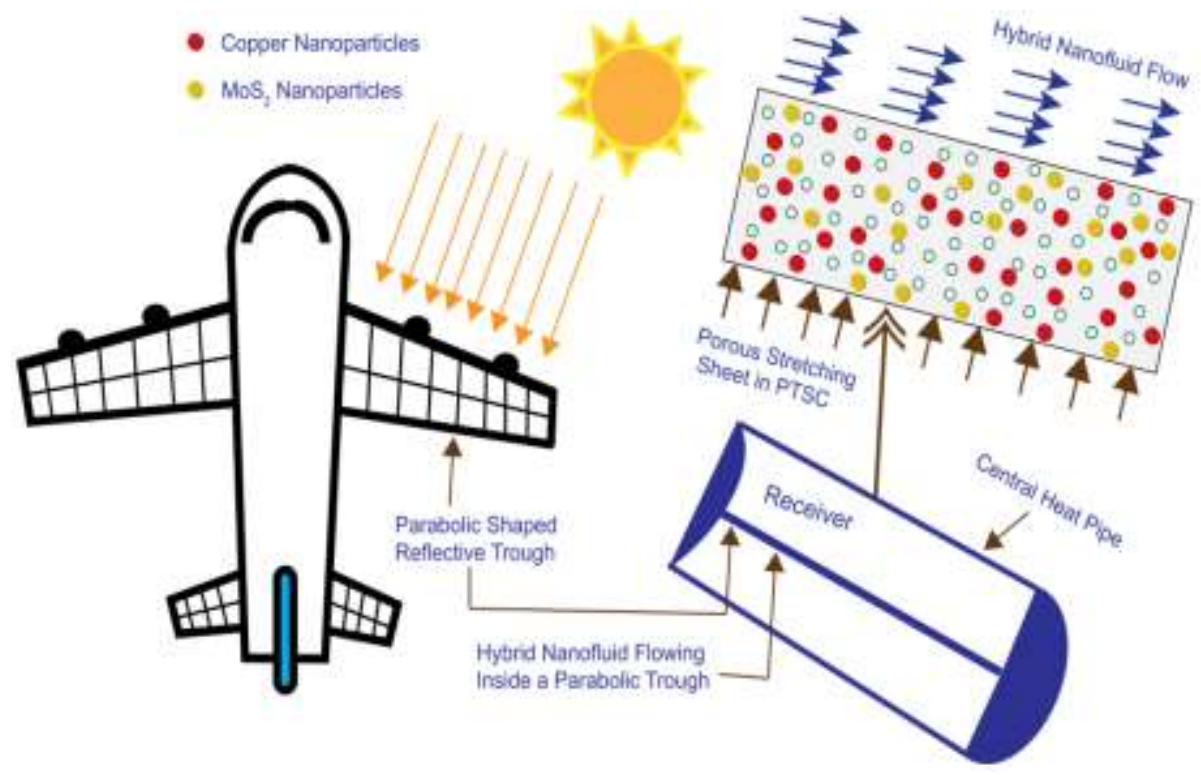

Fig. 1. Simulation of SACW.

Fig. 1 is demonstrated to study the mechanism of heat transport analysis of SACW. Solar radiations fall on the surface of the wings. Radiations penetrated through the wings and scatters on the parabolic through. The PTSC is stretching along $x$-axis with $\mathrm{Cu}-\mathrm{MoS}_{2} / \mathrm{EO}$ type nanofluid flow over the trough surface. Engine oil is considered a base fluid. The symbols like $T_{w}$ and $T_{\infty}$ represents wall as well ambient temperatures respectively. $\mu_{h n f}, \rho_{h n f}, k_{h n f}$ and $\left(C_{p}\right)_{h n f}$ indicates dynamical viscidness, consistency, thermal conductance, and heat capacitance of HNF. Thermophysical features of utilized nanomolecules and base-liquid are demonstrated in Table 1. Fig. 2 represents the diagram planning of the given archetypal.

The controlling formulas regarding the continuity, impetus, and temperature [39] are given in component form as

$$
\begin{aligned}
& \frac{\partial u}{\partial x}+\frac{\partial v}{\partial y}=0 \\
& u \frac{\partial u}{\partial x}+v \frac{\partial u}{\partial y}=\frac{\mu_{h n f}}{\rho_{h n f}} \frac{\partial \tau}{\partial y}-\frac{\mu_{h n f}}{K \rho_{h n f}} u \\
& u \frac{\partial T}{\partial x}+v \frac{\partial T}{\partial y}=\frac{\partial}{\partial y}\left(\frac{k_{h n f}}{\left(\rho C_{p}\right)_{h n f}} \frac{\partial T}{\partial y}\right)-\frac{1}{\left(\rho C_{p}\right)_{h n f}} \frac{\partial q_{r}}{\partial y}+\frac{\mu_{h n f}}{\left.\rho C_{p}\right)_{h n f}}\left(\frac{\partial u}{\partial y}\right)^{2}+\frac{Q_{0}\left(T-T_{\infty}\right)}{\left(\rho C_{p}\right)_{h n f}}
\end{aligned}
$$

with 


$$
\left.\begin{array}{l}
y=0: \quad u=a x^{\frac{1}{3}}, v=0, T=T_{w}, \\
y \rightarrow \infty: \quad u \rightarrow 0, T \rightarrow T_{\infty} .
\end{array}\right\}
$$

Then we consider [40]:

$$
\left.\begin{array}{l}
\rho_{n f}=(1-\phi) \rho_{f}+\phi \rho_{s}, \\
\mu_{n f}=\frac{\mu_{f}}{(1-\phi)^{2.5}}, \\
\left(\rho C_{p}\right)_{n f}=(1-\phi)\left(\rho C_{p}\right)_{f}+\phi\left(\rho C_{p}\right)_{s}, \\
\frac{k_{n f}}{k_{f}}=\left[\frac{\left(k_{s}+(m-1) k_{f}\right)-(m-1) \phi\left(k_{f}-k_{s}\right)}{\left(k_{s}+(m-1) k_{f}\right)+\phi\left(k_{f}-k_{s}\right)}\right],
\end{array}\right\}
$$

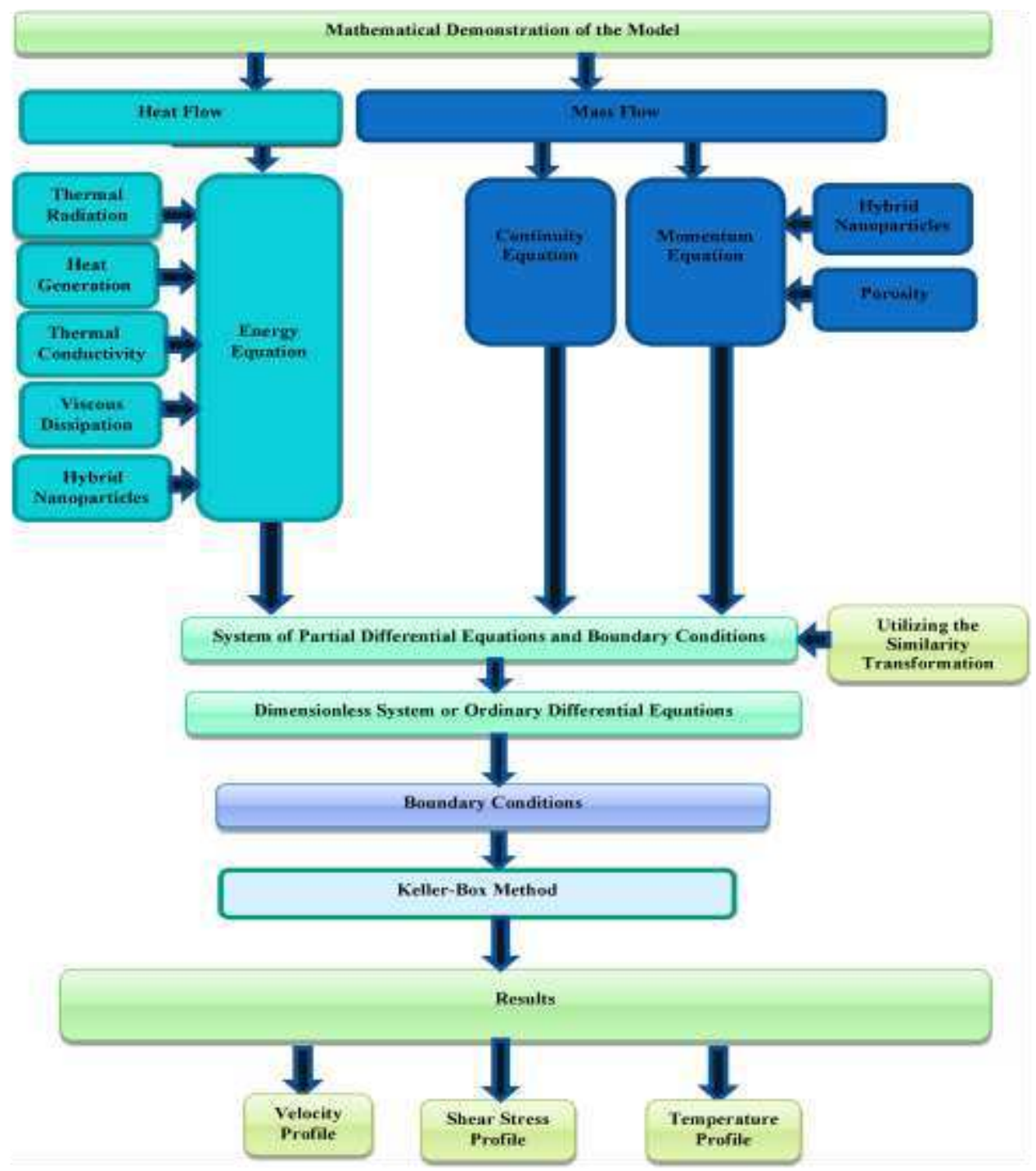

Fig. 2. Simulation of the model. 
Then we construct $[12,18]$ :

$$
\begin{gathered}
\mu_{h n f}=\frac{\mu_{f}}{\left(1-\phi_{1}\right)^{2.5}\left(1-\phi_{2}\right)^{2.5}}, \\
\rho_{n f}=\left[\left(1-\phi_{1}\right) \rho_{f}+\phi_{1} \rho_{s_{1}}\right]\left(1-\phi_{2}\right)+\phi_{2} \rho_{s_{2}}, \\
\left.\left.\left(\rho C_{p}\right)_{h n f}=\left(1-\phi_{2}\right)\left[\phi_{1} \rho C_{p}\right)_{s_{1}}+\left(1-\phi_{1}\right) \rho C_{p}\right)_{f}\right]+\phi_{2}\left(\rho C_{p}\right)_{s_{1}}, \\
\frac{k_{n f}}{k_{f}}=\left[\frac{\left(k_{s_{2}}+(m-1) k_{f}\right)-(m-1) \phi_{2}\left(k_{f}-k_{s_{2}}\right)}{\left(k_{s_{2}}+(m-1) k_{f}\right)+\phi_{2}\left(k_{f}-k_{s_{2}}\right)}\right] \times \\
{\left[\frac{\left(k_{s_{1}}+(m-1) k_{f}\right)-(m-1) \phi_{1}\left(k_{f}-k_{s_{1}}\right)}{\left(k_{s_{1}}+(m-1) k_{f}\right)+\phi_{1}\left(k_{f}-k_{s_{1}}\right)}\right],}
\end{gathered}
$$

\begin{tabular}{|c|c|c|c|}
\hline Features & Engine Oil (EO) & Copper $(\mathrm{Cu})$ & $\left(\mathrm{MoS}_{2}\right)$ \\
\hline$\rho$ & 884 & 8933 & 5060 \\
\hline$C_{p}$ & 1910 & 385 & 397.21 \\
\hline$k$ & 0.144 & 401 & 904.4 \\
\hline
\end{tabular}

Table 1. Thermophysical features.

Then, we get

$$
q_{r}=-\frac{4 \sigma^{*}}{3 \kappa^{*}} \frac{\partial T^{4}}{\partial y}
$$

and

$$
\psi=\sqrt{U(x) x v} f(\eta), \eta=\sqrt{\frac{U(x)}{v x}} y, \tau=\rho \sqrt{U_{0}^{3} v} g(\eta), \theta(\eta)=\frac{T-T_{\infty}}{T_{0}-T_{\infty}}
$$

Thus, we reach

$$
\begin{aligned}
& g^{\prime}=\frac{1}{3 A_{1} A_{2}} f^{\prime 2}-\frac{2}{3} f f^{\prime \prime}-\lambda_{1} f^{\prime}, \\
& g=f^{\prime \prime} \frac{g^{2}+\lambda \gamma^{2}}{g^{2}+\gamma^{2}} \\
& \left\{\left[(1+\epsilon)+\frac{R d}{A_{4}}\right] \theta^{\prime \prime}+\epsilon \theta^{\prime 2}\right\}+\frac{2}{3} \frac{A_{3}}{A_{4}} \operatorname{Pr} f \theta^{\prime}+\frac{A_{1}}{A_{4}} \text { Pr Ec } f^{\prime \prime 2}+\frac{Q}{A_{4}} \theta=0,
\end{aligned}
$$

with

$$
\begin{aligned}
& \eta=0 \quad: f(\eta)=0, \quad f^{\prime}(\eta)=1, \quad \theta^{\prime}(0)=1, \\
& \eta \rightarrow \infty: f^{\prime}(\eta) \rightarrow 0, \quad \theta(\eta) \rightarrow 0 .
\end{aligned}
$$

Finally, we obtain

$$
\left.\begin{array}{l}
\gamma=\left(\frac{\tau_{s}}{\rho \sqrt{U_{0}^{3} v}}\right), \lambda=\frac{\mu_{0}}{\mu_{\infty}}, \operatorname{Pr}=\frac{\mu C_{p}}{k_{\infty}}, R_{d}=\frac{16 \sigma T_{\infty}^{3}}{3 k^{*} k_{\infty}}, \lambda=\frac{v}{K a}, \\
E C=\frac{u_{w}}{C p\left(T_{0}-T_{\infty}\right)}, Q=\frac{Q_{0}\left(T_{0}-T_{\infty}\right)}{\left(\rho C_{p}\right)_{h n f}} .
\end{array}\right\}
$$


We have

$$
C f_{x}=\frac{\tau_{w}}{\rho u_{w}^{2}}, \quad N u_{x}=\frac{x q_{w}}{k_{f}\left(T_{w}-T_{\infty}\right)}
$$

and

$$
\tau_{w}=\mu_{h n f} \tau, q_{w}=-\left[k_{h n f}+\frac{16 \sigma^{*}}{3 \kappa^{*}} T_{\infty}^{3} \frac{\partial T}{\partial y}\right] .
$$

Nonimensional formula of frictional force is demonstrated as:

$$
C f_{x} R e_{x}^{1 / 2}=\frac{g}{A_{1}},
$$

The nondimensional Nusselt number is presented as:

$$
N u_{x} R e_{x}^{-1 / 2}=-A_{4}(1+R d) \theta^{\prime}
$$

whereas $A_{1}, A_{2}, A_{3}$ and $A_{4}$ are given by

$$
\left.\begin{array}{rl}
A_{1}= & \frac{1}{\left(1-\phi_{1}\right)^{2.5}\left(1-\phi_{2}\right)^{2.5}}, \\
A_{2}= & {\left[\left(1-\phi_{1}\right)+\phi_{1} \frac{\rho_{s_{1}}}{\rho_{f}}\right]\left(1-\phi_{2}\right)+\phi_{2} \frac{\rho_{s_{2}}}{\rho_{f}},} \\
A_{3}= & \left.\left(1-\phi_{2}\right)\left[\phi_{1} \frac{\left(\rho C_{p}\right)_{s_{1}}}{\left.\rho C_{p}\right)_{f}}\right)+\left(1-\phi_{1}\right)\right]+\phi_{2} \frac{\left(\rho C_{p}\right)_{s_{2}}}{\left.\rho C_{p}\right)_{f}}, \\
A_{4}= & {\left[\frac{\left(k_{s 2}+(m-1) k_{f}\right)-(m-1) \phi_{2}\left(k_{f}-k_{s_{2}}\right)}{\left(k_{s_{2}}+(m-1) k_{f}\right)+\phi_{2}\left(k_{f}-k_{s_{2}}\right)}\right] \times} \\
& {\left[\frac{\left(k_{s_{1}}+(m-1) k_{f}\right)-(m-1) \phi_{1}\left(k_{f}-k_{s_{1}}\right)}{\left(k_{s_{1}}+(m-1) k_{f}\right)+\phi_{1}\left(k_{f}-k_{s_{1}}\right)}\right]}
\end{array}\right\}
$$

Table 2 shows comparing of the consequences with Ref. [41] for diverse values of $\gamma$.

Table 2. Comparing of the consequences with Ref. [41].

\begin{tabular}{lllll}
\hline \multicolumn{5}{c}{$N u_{x} R e_{x}^{\frac{-1}{2}}($ Absent $R d)$} \\
\hline$\gamma$ & $\lambda=0.5$ & & \multicolumn{2}{c}{$\lambda=1$} \\
\hline 0.1 & Current & Reddy [41] & Current & Reddy [41] \\
0.2 & 0.130909 & 0.109782 & 0.144535 & 0.114058 \\
0.3 & 0.109284 & 0.102621 & 0.144535 & 0.114058 \\
\hline
\end{tabular}

\section{Numerical Procedure}

Fig. 3 shows the procedure diagram of the numerical KBT. 


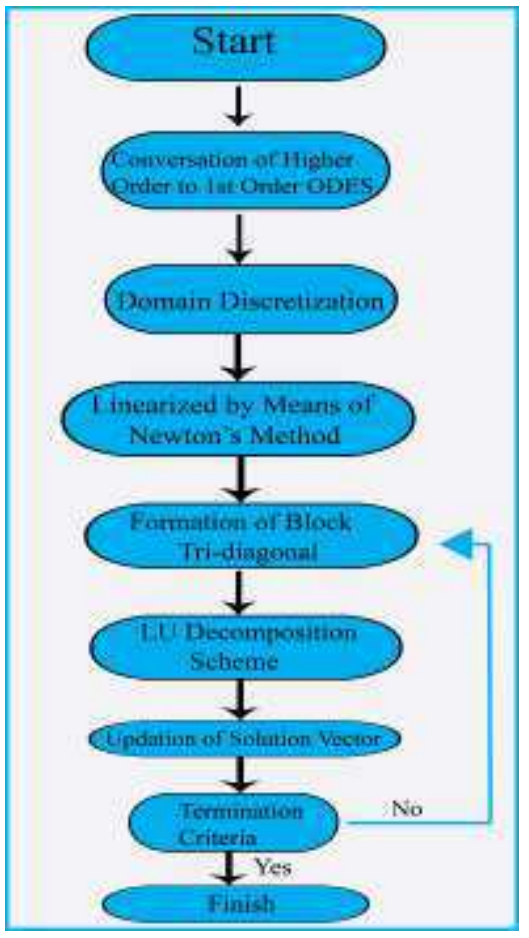

Fig. 3. KBT diagram.

We have

$$
\begin{aligned}
& \frac{d f}{d \eta}=u_{1} \\
& \frac{d \widetilde{u}_{1}}{d \eta}=u_{2} \\
& \frac{d \theta}{d \eta}=u_{3} \\
& \frac{d u_{2}}{d \eta}-\frac{g^{2}+r^{2}}{g^{2}+\lambda r^{2}}\left[\frac{1}{A_{1} A_{2}} u_{1}^{2}-\frac{2}{3} f u_{2}-\lambda_{1} u_{1}\right]=0
\end{aligned}
$$

and

$$
\left.\begin{array}{c}
\left((1+\epsilon)+\frac{R d}{A_{4}}\right) \frac{d u_{3}}{d \eta}+\epsilon u_{3}^{2}+\frac{2 A_{3}}{3 A_{4}} \operatorname{Prf} u_{3}+\operatorname{PrEc} \frac{A_{1}}{A_{4}} u_{2}^{2}+\frac{Q}{A_{4}} \theta=0 . \\
\begin{array}{c}
f(0)=0, u_{1}(0)=1, u_{3}(0)=1, \\
u_{1} \rightarrow 0, \quad \theta \rightarrow 0
\end{array} \text { as } \quad \eta \rightarrow \infty .
\end{array}\right\}
$$




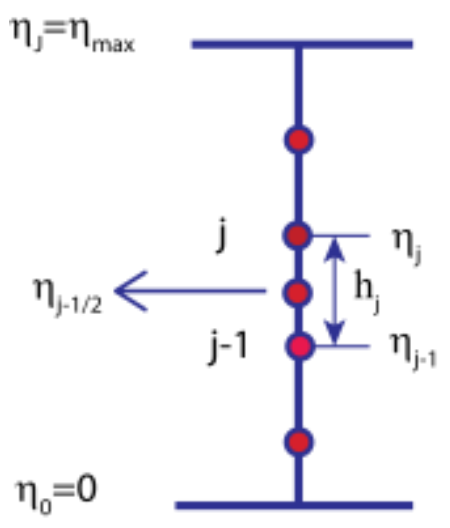

Fig. 4. Domain discretization.

We have

$$
\eta_{0}=0, \quad \eta_{j}=\eta_{j-1}+h_{j}, j=0,1,2,3 \ldots, J, \quad \eta_{J}=\eta_{\infty} \text { where, } h_{j} \text { is the step-size }
$$

(Fig. 4). Then, we reach

$$
\begin{aligned}
& \frac{f_{j}-f_{j-1}}{h_{j}}-\frac{\left(u_{1}\right)_{j}+\left(u_{1}\right)_{j-1}}{2}=0, \\
& \frac{\left(u_{1}\right)_{j}-\left(u_{1}\right)_{j-1}}{h_{j}}-\frac{\left(u_{2}\right)_{j}+\left(u_{2}\right)_{j-1}}{2}=0, \\
& \frac{\theta_{j}-\theta_{j-1}}{h_{j}}-\frac{\left(u_{3}\right)_{j}+\left(u_{3}\right)_{j-1}}{2}=0 \text {, } \\
& \left.\left(\left(u_{2}\right)_{j}-\left(u_{2}\right)_{j-1}\right)-\frac{h_{j}}{2} \frac{g^{2}+r^{2}}{g^{2}+\lambda r^{2}}\left[\frac{1}{3 A_{1} A_{2}}\left(\frac{\left(u_{1}\right)_{j}+\left(u_{1}\right)_{j-1}}{2}\right)^{2}\right]+\frac{h_{j}}{2} \frac{g^{2}+r^{2}}{g^{2}+\lambda r^{2}}\right) \\
& \left.\lambda_{1}\left(\frac{\left(u_{1}\right)_{j}+\left(u_{1}\right)_{j-1}}{2}\right)+\frac{h_{j}}{3} \frac{g^{2}+r^{2}}{g^{2}+\lambda r^{2}}\left(f_{j}+f_{j-1}\right)\left(\left(u_{1}\right)_{j}+\left(u_{1}\right)_{j-1}\right)=0\right\} \text {, } \\
& \left.\left((1+\epsilon)+\frac{R d}{A_{4}}\right)\left(\left(u_{3}\right)_{j}-\left(u_{3}\right)_{j-1}\right)+\epsilon h_{j}\left(\frac{\left(u_{3}\right)_{j}+\left(u_{3}\right)_{j-1}}{2}\right)^{2}\right) \\
& +\frac{2 h_{j} A_{3} P r}{3 A_{4}}\left(\frac{f_{j}+f_{j-1}}{2}\right)\left(\frac{\left(u_{3}\right)_{j}+\left(u_{3}\right)_{j-1}}{2}\right) \\
& \left.+\frac{h_{j} \operatorname{PrEc} A_{1}}{A_{4}}\left(\frac{\left(u_{2}\right)_{j}+\left(u_{2}\right)_{j-1}}{2}\right)^{2}+h_{j} \frac{Q}{A_{4}}\left(\frac{\theta_{j}+\theta_{j-1}}{2}\right)=0 . \quad\right)
\end{aligned}
$$

The nonlinearity formulas (28)-(32) structure should be linearized by the Newton method. We have

$$
\begin{aligned}
& f_{j}^{n+1}=f_{j}^{n}+\delta f_{j}^{n}, \quad\left(u_{1}\right)_{j}^{n+1}=\left(u_{1}\right)_{j}^{n}+\delta\left(u_{2}\right)_{j}^{n}, \quad\left(u_{2}\right)_{j}^{n+1}=\left(u_{2}\right)_{j}^{n}+\delta\left(u_{2}\right)_{j}^{n}, \\
& \left(u_{3}\right)_{j}^{n+1}=\left(u_{3}\right)_{j}^{n}+\delta\left(u_{3}\right)_{j}^{n}, \quad \theta_{j}^{n+1}=\theta_{j}^{n}+\delta \theta_{j}^{n} .
\end{aligned}
$$

Then, we obtain

$$
\begin{aligned}
& \delta f_{j}-\delta f_{j-1}-\frac{h_{j}}{2}\left(\delta\left(u_{1}\right)_{j}+\delta\left(u_{1}\right)_{j-1}\right)=\left(r_{1}\right)_{j}, \\
& \delta\left(u_{1}\right)_{j}-\delta\left(u_{1}\right)_{j-1}-\frac{h_{j}}{2}\left(\delta\left(u_{2}\right)_{j}+\delta\left(u_{2}\right)_{j-1}\right)=\left(r_{2}\right)_{j},
\end{aligned}
$$




$$
\begin{aligned}
& \delta \theta_{j}-\delta \theta_{j-1}-\frac{h_{j}}{2}\left(\delta\left(u_{3}\right)_{j}+\delta\left(u_{3}\right)_{j-1}\right)=\left(r_{3}\right)_{j} \\
& \left(a_{1}\right)_{j} \delta f_{j}+\left(a_{2}\right)_{j} \delta f_{j-1}+\left(a_{3}\right)_{j} \delta\left(u_{1}\right)_{j}+\left(a_{4}\right)_{j} \delta\left(u_{1}\right)_{j-1}+\left(a_{5}\right)_{j} \delta\left(u_{2}\right)_{j}+\left(a_{6}\right)_{j} \delta\left(u_{2}\right)_{j-1}= \\
& \left(r_{4}\right)_{j}, \\
& \left(b_{1}\right)_{j} \delta f_{j}+\left(b_{2}\right)_{j} \delta f_{j-1}+\left(b_{3}\right)_{j} \delta\left(u_{2}\right)_{j}+\left(b_{4}\right)_{j} \delta\left(u_{2}\right)_{j-1}+\left(b_{5}\right)_{j} \delta\left(u_{3}\right)_{j}+\left(b_{6}\right)_{j} \delta\left(u_{3}\right)_{j-1}+ \\
& \left(b_{7}\right)_{j} \delta \theta_{j}+\left(b_{8}\right)_{j} \delta \theta_{j-1}=\left(r_{5}\right)_{j},
\end{aligned}
$$

where

$$
\left.\begin{array}{l}
\left(a_{1}\right)_{j}=\frac{2 h_{j}}{3} \frac{g^{2}+r^{2}}{g^{2}+\lambda r^{2}} \frac{\left(\left(u_{2}\right)_{j}+\left(u_{2}\right)_{j-1}\right)}{4}, \quad\left(a_{2}\right)_{j}=\left(a_{1}\right)_{j}, \\
\left(a_{3}\right)_{j}=\frac{h_{j} \lambda_{1}}{2} \frac{g^{2}+r^{2}}{g^{2}+\lambda r^{2}}-\frac{h_{j}}{3 A_{1} A_{2}} \frac{g^{2}+r^{2}}{g^{2}+\lambda r^{2}} \frac{\left(\left(u_{1}\right)_{j}+\left(u_{1}\right)_{j-1}\right)}{2}=\left(a_{4}\right)_{j} \\
\left(a_{5}\right)_{j}=1+\frac{2 h_{j}}{3} \frac{g^{2}+r^{2}}{g^{2}+\lambda r^{2}} \frac{\left(f_{j}+f_{j-1}\right)}{4}=\left(a_{6}\right)_{j}, \\
\left(r_{4}\right)_{j}=-\frac{h_{j} \lambda_{1}}{2} \frac{g^{2}+r^{2}}{g^{2}+\lambda r^{2}}\left(\left(u_{1}\right)_{j}+\left(u_{1}\right)_{j-1}\right)+\frac{h_{j}}{12 A_{1} A_{2}} \frac{g^{2}+r^{2}}{g^{2}+\lambda r^{2}}\left(\left(u_{1}\right)_{j}+\left(u_{1}\right)_{j-1}\right)^{2}=\left(b_{1}\right)_{j}, \\
-\frac{h_{j}}{6} \frac{g^{2}+r^{2}}{g^{2}+\lambda r^{2}}\left(f_{j}+f_{j-1}\right)\left(\left(u_{2}\right)_{j}+\left(u_{2}\right)_{j-1}\right)-\left(\left(u_{2}\right)_{j}-\left(u_{2}\right)_{j-1}\right)_{j}, \\
\left(b_{1}\right)_{j}=\frac{2 h_{j} \operatorname{Pr} A_{3}}{3 A_{4}} \frac{\left(\left(u_{3}\right)_{j}+\left(u_{3}\right)_{j-1}\right)}{4}, \\
\left(b_{3}\right)_{j}=\frac{h_{j} P r A_{1} E c}{A_{4}} \frac{\left(\left(u_{2}\right)_{j}+\left(u_{2}\right)_{j-1}\right)}{2}, \\
\left(b_{5}\right)_{j}=\left((1+\epsilon)+\frac{R d}{A_{4}}\right)+\frac{2 h_{j} P r A_{3}}{3 A_{4}} \frac{\left(f_{j}+f_{j-1}\right)}{4}+\epsilon h_{j} \frac{\left(\left(u_{3}\right)_{j}+\left(u_{3}\right)_{j-1}\right)}{2}, \\
\left(b_{6}\right)_{j}=-\left((1+\epsilon)+\frac{R d}{A_{4}}\right)+\frac{2 h_{j} P r A_{3}}{3 A_{4}} \frac{\left(f_{j}+f_{j-1}\right)}{4}+\epsilon h_{j} \frac{\left(\left(u_{3}\right)_{j}+\left(u_{3}\right)_{j-1}\right)}{2}, \\
\left(b_{7}\right)_{j}=\frac{1}{2} \frac{h_{j} Q}{A_{4}}=\left(b_{8}\right)_{j}, \\
\left(r_{6}\right)_{j}=-\left((1+\epsilon)+\frac{R d}{A_{4}}\right)\left(\left(u_{3}\right)_{j}-\left(u_{3}\right)_{j-1}\right)-\epsilon h_{j}\left(\frac{\left(u_{3}\right)_{j}+\left(u_{3}\right)_{j-1}}{2}\right)^{2} \\
-\frac{2 h_{j} A_{3} P r}{3 A_{4}}\left(\frac{f_{j}+f_{j-1}}{2}\right)\left(\frac{\left(u_{3}\right)_{j}+\left(u_{3}\right)_{j-1}}{2}\right) \\
-\frac{h_{j} \operatorname{PrEcA_{1}}}{A_{4}}\left(\frac{\left(u_{2}\right)_{j}+\left(u_{2}\right)_{j-1}}{2}\right)^{2}-h_{j} \frac{Q}{A_{4}}\left(\frac{\theta_{j}+\theta_{j-1}}{2}\right) . \\
2
\end{array}\right\}
$$

Then, we get

$$
A \delta=R \text {, }
$$

where 


$$
A=\left[\begin{array}{ccccccc}
{\left[A_{1}\right]} & {\left[C_{1}\right]} & & & & & \\
& {\left[A_{2}\right]} & {\left[C_{2}\right]} & & & & \\
& & & \ddots & & & \\
& & & \ddots & & & \\
& & & & {\left[B_{J-1}\right]} & {\left[A_{J-1}\right]} & {\left[C_{J-1}\right]} \\
& & & & & {\left[B_{J}\right]} & {\left[A_{J}\right]}
\end{array}\right], \delta=\left[\begin{array}{l}
{\left[\delta_{1}\right]} \\
\vdots \\
\vdots \\
\vdots
\end{array}\right] \text { and } R=\left[\begin{array}{l}
{\left[R_{1}\right]} \\
\vdots \\
\vdots \\
\vdots
\end{array}\right] \text {. }
$$

where the elements defined in Eq. (38) are

$$
\begin{aligned}
& {\left[A_{1}\right]=3 p t\left[\begin{array}{lllll}
0 & 0 & 1 & 0 & 0 \\
-0.5 h_{1} & 0 & 0 & -0.5 h_{1} & 0 \\
0 & -0.5 h_{1} & 0 & 0 & -0.5 h_{1} \\
\left(a_{6}\right)_{1} & 0 & \left(a_{1}\right)_{1} & \left(a_{5}\right)_{1} & 0 \\
\left(b_{4}\right)_{1} & \left(b_{6}\right)_{1} & \left(b_{1}\right)_{1} & \left(b_{3}\right)_{1} & \left(b_{5}\right)_{1}
\end{array}\right],} \\
& {\left[A_{j}\right]=3 p t\left[\begin{array}{lllll}
-0.5 h_{j} & 0 & 1 & 0 & 0 \\
-1 & 0 & 0 & -0.5 h_{j} & 0 \\
0 & -1 & 0 & 0 & -0.5 h_{j} \\
\left(a_{4}\right)_{j} & 0 & \left(a_{1}\right)_{j} & \left(a_{5}\right)_{j} & 0 \\
0 & \left(b_{8}\right)_{j} & \left(b_{1}\right)_{j} & \left(b_{3}\right)_{j} & \left(b_{5}\right)_{j}
\end{array}\right], 2 \leq j \leq J} \\
& {\left[B_{j}\right]=10 p t\left[\begin{array}{lllll}
0 & 0 & -1 & 0 & 0 \\
0 & 0 & 0 & -0.5 h_{j} & 0 \\
0 & 0 & 0 & 0 & -0.5 h_{j} \\
0 & 0 & \left(a_{2}\right)_{j} & \left(a_{6}\right)_{j} & 0 \\
0 & 0 & \left(b_{2}\right)_{j} & \left(b_{4}\right)_{j} & \left(b_{6}\right)_{j}
\end{array}\right], 2 \leq j \leq J} \\
& {\left[C_{j}\right]=8 p t\left[\begin{array}{lllll}
-0.5 h_{j} & 0 & 0 & 0 & 0 \\
1 & 0 & 0 & 0 & 0 \\
0 & 1 & 0 & 0 & 0 \\
\left(a_{3}\right)_{j} & 0 & 0 & 0 & 0 \\
0 & \left(b_{7}\right)_{j} & 0 & 0 & 0
\end{array}\right], 1 \leq j \leq J-1 .}
\end{aligned}
$$

Factorizing $A$ as

$$
A=L U \text {, }
$$

where 


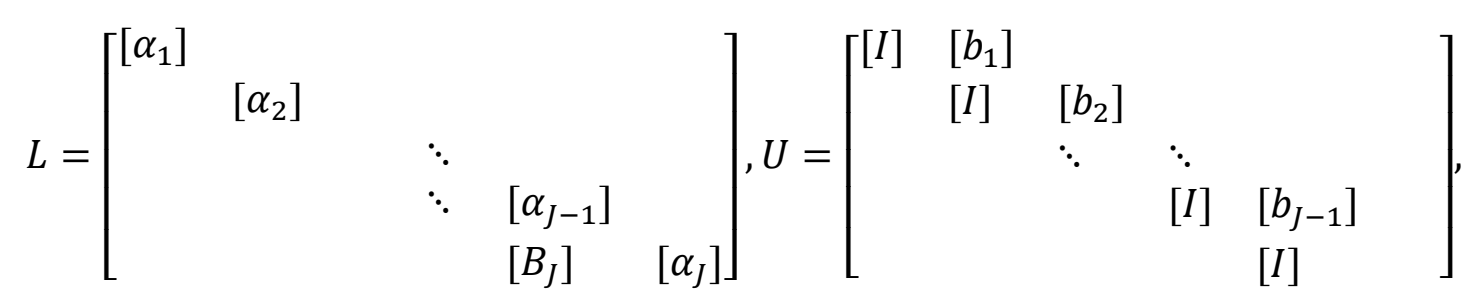

here $[I]$ signfies the unity matrix with $\mathrm{O}(5),\left[\alpha_{i}\right],\left[B_{i}\right]$ and $\left[b_{i}\right]$ are $5 \times 5$ matrices. We have

$$
E_{\mathrm{g}}=\frac{k_{n f}}{T_{\infty}^{2}}\left(\left(\frac{\partial T}{\partial y}\right)^{2}+\frac{16 \sigma^{*} T_{\infty}^{3}}{3 \kappa^{*}}\left(\frac{\partial T}{\partial y}\right)^{2}\right)+\frac{\mu_{n f}}{T_{\infty}}\left(\frac{\partial u}{\partial y}\right)^{2}+\frac{\mu_{n f}}{T_{\infty}} u^{2}
$$

and

$$
N_{\mathrm{g}}=\frac{T_{\infty}^{2} a^{2} E_{G}}{\kappa_{f}\left(T_{w}-T_{\infty}\right)^{2}}
$$

the dimensionless expression regarding entropy generation is bestowed by

$$
N_{\mathrm{g}}=\operatorname{Re}\left(A_{4}(1+R d) \theta^{\prime 2}+\frac{1}{A_{1}} \frac{B r}{\Omega}\left(f^{\prime \prime 2}+\lambda_{1} f^{\prime 2}\right)\right)
$$

\section{Results and Discussions}

Figs. 5-8 design to reverberate the performance of RPNF parameter $\lambda$ on the velocites $f^{\prime}(\eta)$, $g(\eta)$, and temperature $\theta(\eta)$ and entropic production $N_{\mathrm{g}}$. The viscosity of the fluid debacles by the virtue of an amplification in $\lambda$ which contribute towards the minimization of fluid viscosity and speed of the nanofluid as well. It is quite interesting that the shear stress of the fluid lessens for the case an augmentation in $\lambda$ consequently diminishes $g(\eta)$. It is observed that the viscosity of the fluid diminishes by amplifying fluid temperature and the fluid behaves like shear thinning which improves the temperature phenomenon of the fluid $\theta(\eta)$. An amplification in temperature means the fluid particles possess enormous kinetic energy. It means that the particles moving faster brings about more disorder in comparison to particles in fluid moving with lower speed. Thats why an embellishment in temperature booms entropy $N_{\mathrm{g}}$. It is also observed that the hybrid nanoparticles particles amplifies temperature and entropy much better in contrast to the simple nanofluid.

Figs. 9-12 sway the impact of Bingham factor $\gamma$ on $f^{\prime}(\eta), g(\eta), \theta(\eta)$ and $N_{\mathrm{g}}$. Bingham number is the ratio between yield stress as well as viscidness-stress. All of $\lambda$ and $\gamma$ are essential factors of RPNF and almost behaves in a same manner. It is noted that a enlargement in viscidness lessens the yield-stress and improves $\gamma$ and furthermore behaves like shear-thinning. As a result a shear thinning phenomenon, the fluid flow over the surface which amplifies the velocity and shea stress domain. Viscidness of the nanofluid depreciates on the account of magnification in $\gamma$. The 
temperature phenomenon is contrarywise associated to the nanofluid viscosity. Decremental change in nanofluid viscidness drives to a enlargement in the fluid temperature. Global the entropic rate of the nanofluid booms due to an amplification in the temperature phenomenon.

The effect of Reynold Re, Brinkman $B r$ numbers and $\Omega$ on entropic production $N_{\mathrm{g}}$ is highlighted in Figs. 13-15. It is quite clear that the viscous forces becomes less dominant as compared to inertial forces in the status of an augmentation variation in $R e$. As a result of inertial forces dominance over viscous produces a magnification in temperature which elevates $N_{\mathrm{g}}$. The relation between $\mathrm{Br}$ and $N_{\mathrm{g}}$ is highlighted in Fig. 14. Brinkman number $\mathrm{Br}$ can be defined as heat dissipation to the conduction. It is noted that the considerable heat is dissipated on the account of an increment in $\mathrm{Br}$ elevates entropy of the system. The impact of dimensionless temperature variations $\Omega$ on $N_{\mathrm{g}}$ is displayed in Fig. 15. It is observed that the heat dissipation process amplifies on the account of an amplification in $\Omega$ which diminishes $N_{\mathrm{g}}$. The effect of porosity parameter $\lambda_{1}$ on $f^{\prime}(\eta), g(\eta), \theta(\eta)$ and $N_{\mathrm{g}}$ is emphasized in Figs. 16-18.

Figs. 19 and 20 reflect the impact of thermal conductance $\epsilon$. When molecules of the fluid collides more randomly exchange much kinetic energy with each other in comparison to normal collision which eventually produces much heat inside the fluid. On other hand due to this frequent collision of the molecules the temperature of the fluid amplifies which augments temperature field and entropy $\theta(\eta)$ and $N_{\mathrm{g}}$.

Fig. 21 and 22 reflects the influence of Prandtl number $\operatorname{Pr}$ on $\theta(\eta)$ and $N_{\mathrm{g}}$. Thermal conductance of the nanofluid debacles in the status of a amplification in $\operatorname{Pr}$ which lessens the temperature of the fluid as well. Prandtl is impetus diffusion to thermal diffusion. Impetus diffusion predominants thermal diffusion which brings about a decrement in temperature. Thermal boundary thickness decreases and decreases more in the case of $N_{\mathrm{g}}$.

Figs. 23 and 24 are designed to reveal the impact of Eckert number $E c$ on the heat field $\theta(\eta)$ and entropic production. The parameter $E c$ is actually kinetical energy to enthalpic variance. A positive variation in kinetical energy enhances heat transfer phenomenon. Nanomolecules shock extra at random due to a development in the kinetic energy. Internal heat generation capacity of the fluid improves by the virtue of an amplification in $E c$. The PTSC transports heat more effectively within SACW because of a variation of $E c$ values. When solar thermal radiations fall on the trough present in the wing, the nanoparticles present on the trough surface collides more frequently and 
heating capacity of the trough improves and distribute heat quite effectively inside the wings and other parts of the aircraft. generation capacity of the fluid. From this figure, the mixture nanomolecules delivers well the heat in contrast to simple nanofluid.

Internal heat generation $Q$ and $R d$ on $\theta(\eta)$ and $N_{\mathrm{g}}$ are emphasized in Figs. 25-28. Thermal boundary thickness along with the heat transmission of the hybrid-nanofluid is better in contrast to simple nanofluid. A positive change in $Q$ generates more inside the fluid which improves thermal transport process of the nanofluid. When solar radiations fall on the surface of the parabolic trough. The internal heat generation capacity of the trough improves and provides extensive heat to the nanoparticles based fluid. The heat delivers effectively in the situation of mixture nanomolecules based liquid in contrast to the natural base fluid. Radiations are the main source of heat energy. Solar thermal radiations have change the whole concept of the renewable energy and provides different ideas to the researchers to work on the ideas of solar air craft wings, solar water pumps, solar motor bikes etc. When these solar radiations continuously fall on the surface of the trough, it delivers extensive to the nanoliquid flowing over PTSC. Thermal conduction process of the fluid improves in the case of magnification in $R d$ which elevates temperature phenomenon. The heat besides total entropic rate of the model improves owing to a magnification in $R d$ and heat generation $Q$.

The effect of volume fractions of nanoparticles $\phi_{h n f}$ on flowing speed $f^{\prime}(\eta)$, shear-stress $g(\eta)$, temperature $\theta(\eta)$ fields and entropic production $N_{\mathrm{g}}$ are highlighted in Figs. 29-32. The concentration of the nanoparticles amplifies on the behalf of an benefication in $\phi_{h n f}$ which elevates the velocity field. The inertial forces dominate viscous forces which diminishes the shear stress behaviour of the fluid and moreover $g(\eta)$. The augmentation in size of nanomolecules enhances thermal conductance over and above the rate of heat transport of the fluid. Insertion of nanomolecules in the normal liquid boosts heat conductance of the base liquid. Thickness of the thermal boundary layer in addition to the rate of heat transmission of the improves by the virtue of an augmentation in nanomolecules size. The solar radiations along with $\phi_{h n f}$ enhances the over all performance of parabolic trough surface collector and delivers heat effectively inside the air craft wings. Consequently $\theta(\eta)$ and $N_{\mathrm{g}}$ amplifies.

The effect of parameter $m$ mention diverse forms of nanomolecules in the form of sphere having value $m=3$, hexadron $=3.7221$, tetrhedron $=4.0613$ and column $=6.3698$ on temperature $\theta(\eta)$ as well as $N_{\mathrm{g}}$ is depicted in Figs. 33 and 34. It is observed that an incremental 
change in $m$ improves temperature along with the rate of heat transport rate of the nanoliquid. Sphere occupy more space in comparison to other shapes of nanoparticles. The column shape nanoparticles 6.3698 produces much heat and temperature of the nanoparticles escalates in comparison to other shapes of nanoparticles. The column shape nanoparticles occupy less space in contrast to sphere. From figure it is quite clear that the thermal boundary thickness of the fluid improves in the case of vertical column in comparison to other shapes. A positive change in $m$ and hybrid nanoparticles $\mathrm{Cu}-\mathrm{MoS}_{2}$ delivers considerable heat collect by the PTSC and transfer in through out the aircraft wing.

Table 3 is sketched to work the effect of many various variables on the frictional force coefficient $C_{f}$ and the rate of heat transmission $\mathrm{Nu}$ in the situation of mixture nano-fluid and standard nano-fluid. The frictional force factor improves in the status of liquid factor $\lambda$ nonetheless diminishes for Bingham number $\gamma$ and porosity parameter $\lambda_{1}$. No change is reported for the case of remaining parameter. From this table the hybrid nanomolecules delivers well results in comparing to the standard nanoliquid. The thermal transfer rate improves in the case of $\lambda, \lambda_{1}$, variant thermal conductance $\epsilon$, Prandtl number $\operatorname{Pr}$, heat generation $Q$, thermal radiative flow $R d$, nanomolecules form $m$, mixture nanofluid $\phi_{h n f}$ and nano-solid particles size of $\phi$. These parameters elevates the performance of nanofluid flow over a PTSC present in SACW.

Table 4 reported the effect of energy parameters $\epsilon, \operatorname{Pr}, E c Q, R d$ on the heat transfer for the situation of hybridity nanoliquid $\mathrm{Cu}-\mathrm{MoS}_{2} / \mathrm{EO}$ and simple nanoliquid $\mathrm{Cu} / \mathrm{EO}$. Error ratio depicts the difference between simple nanofluid and hybrid nanofluid in relation with heat transmission rate. The percentage rate of heat transmission of the $E c$ and $R d$ is greater $14.7 \%$ in comparison to other parameters value. 


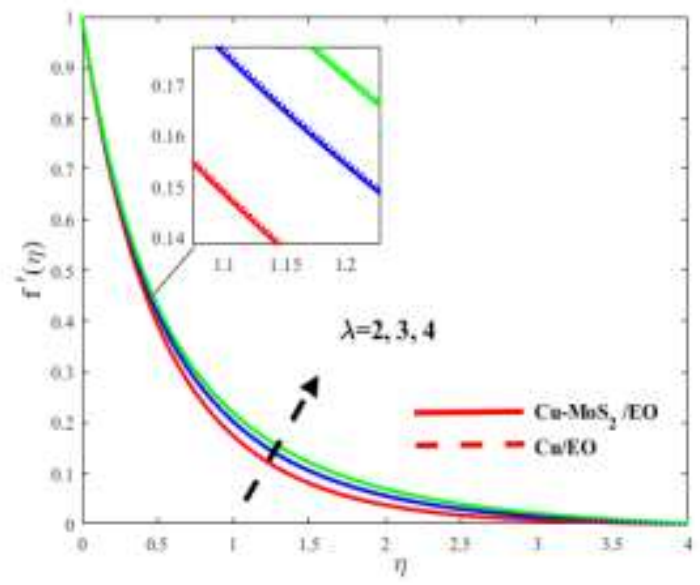

Fig. 5. Impression of $\lambda$ on $f^{\prime}(\eta)$.

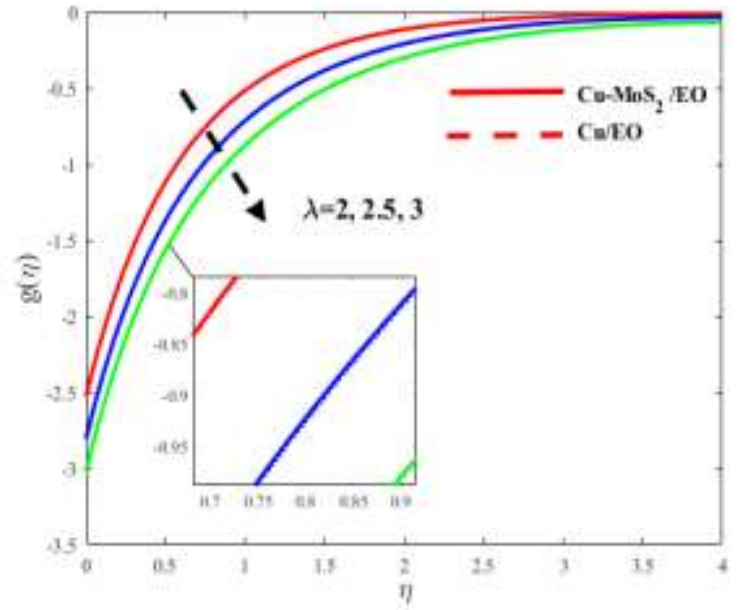

Fig. 6. Impression of $\lambda$ on $g(\eta)$.

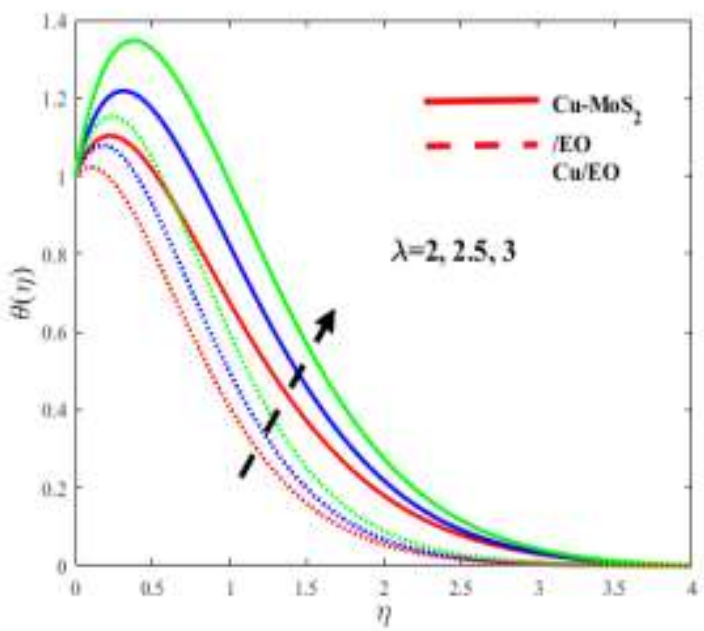

Fig. 7. Impression of $\lambda$ on $\theta(\eta)$. 


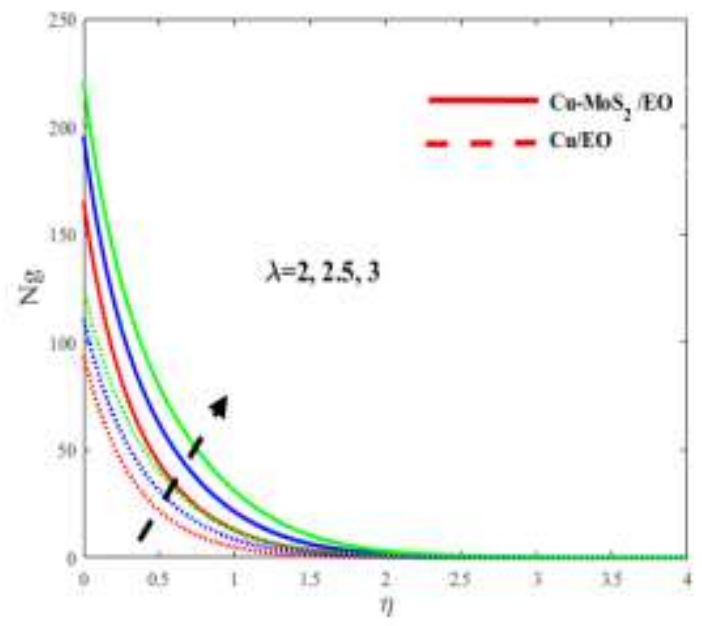

Fig. 8. Impression of $\lambda$ on $N_{\mathrm{g}}$.

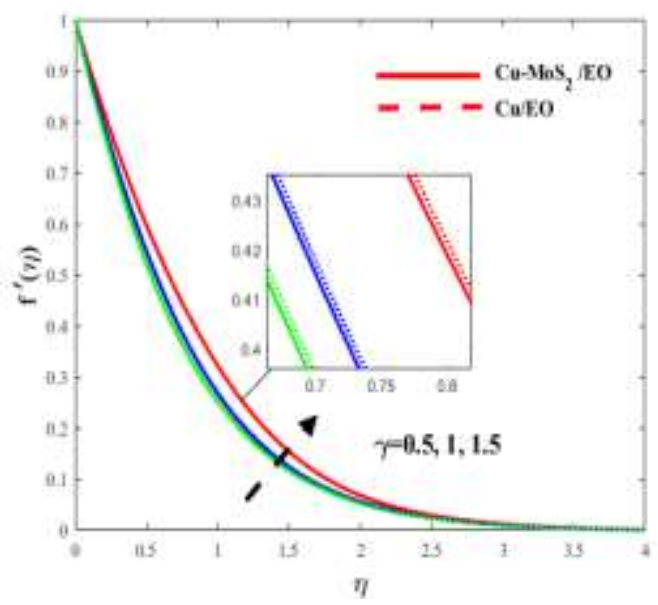

Fig. 9. Impression of $\gamma$ on $f^{\prime}(\eta)$.

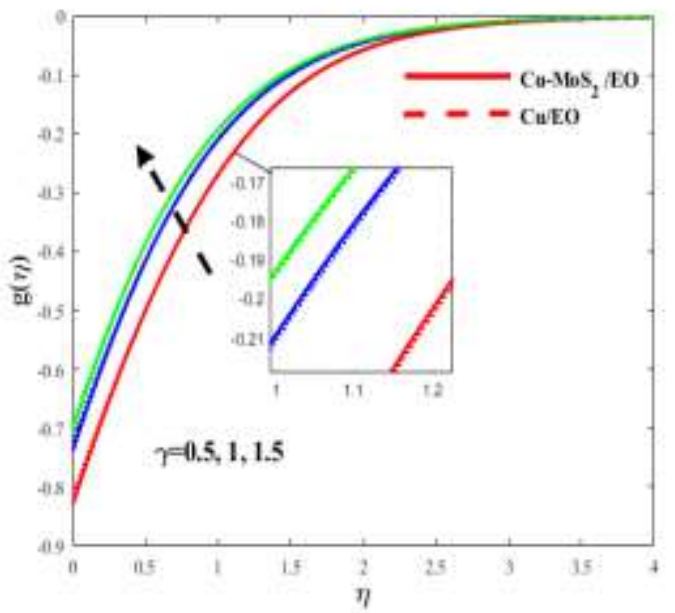

Fig. 10. Impression of $\gamma$ on $g(\eta)$. 


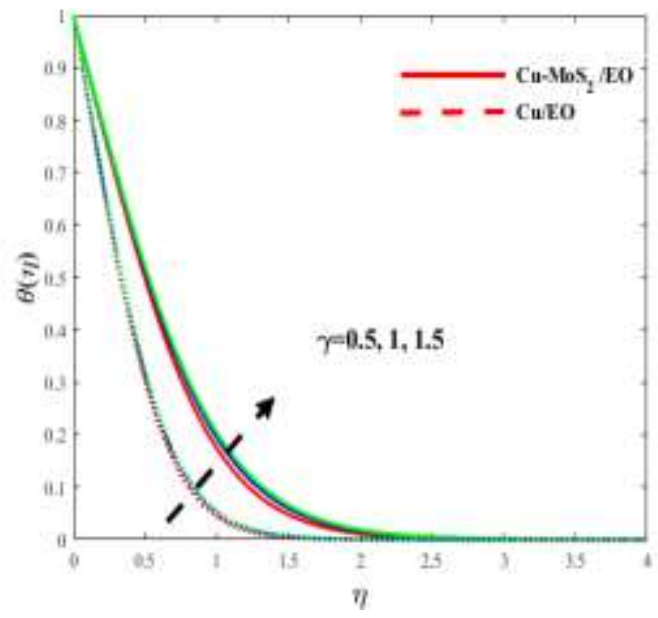

Fig. 11. Impression of $\gamma$ on $\theta(\eta)$.

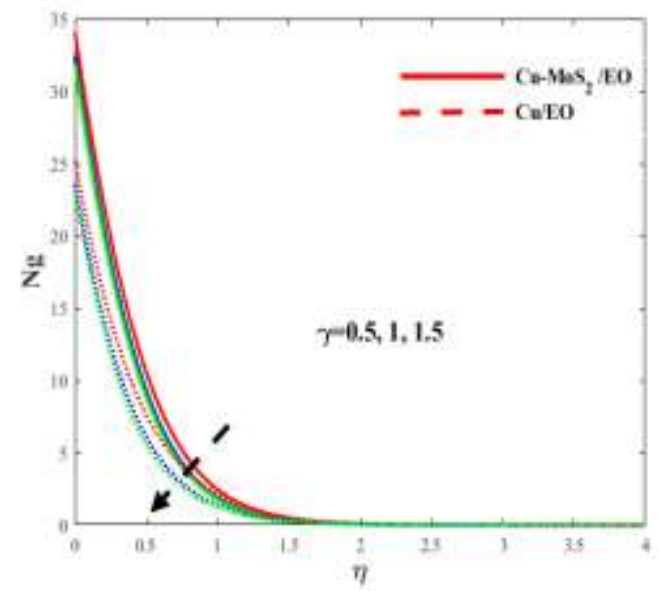

Fig. 12. Impression of $\gamma$ on $N_{\mathrm{g}}$.

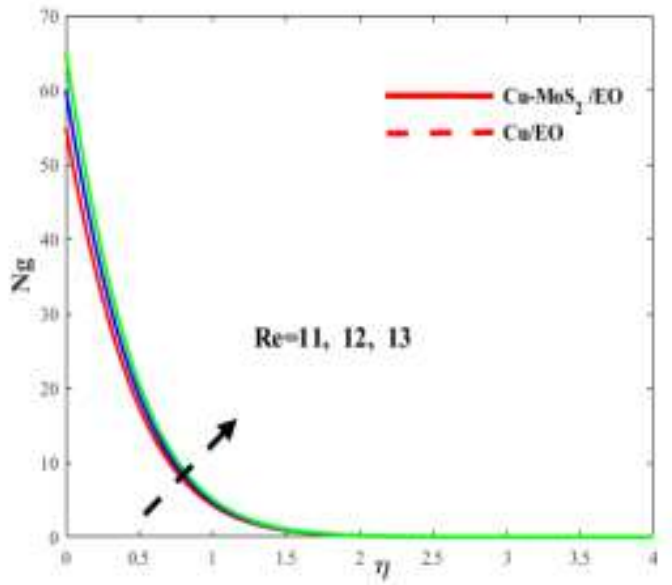

Fig. 13. Impression of $R e$ on $N_{\mathrm{g}}$. 


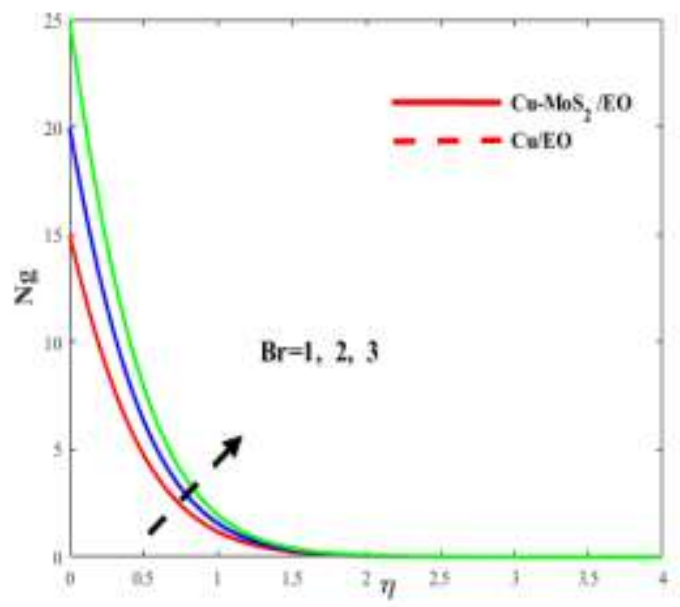

Fig. 14. Impression of $\mathrm{Br}$ on $N_{\mathrm{g}}$.

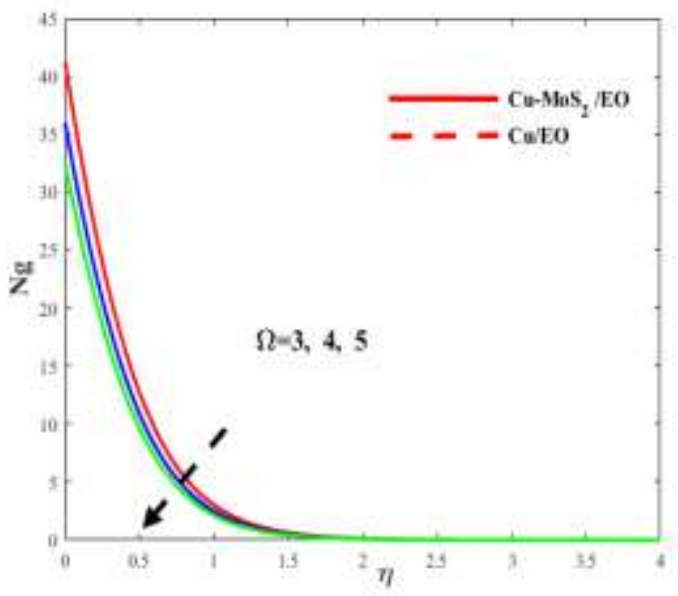

Fig. 15. Effect of $\Omega$ on $N_{\mathrm{g}}$.

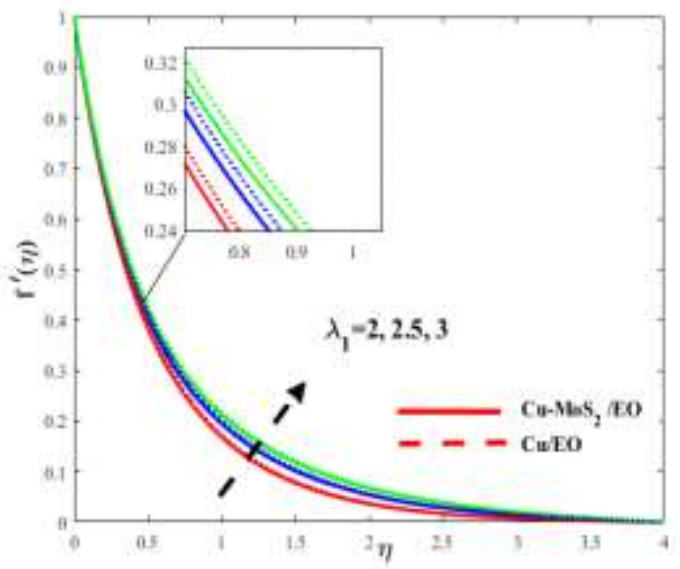

Fig. 16. Effect of $\lambda_{1}$ on $f^{\prime}(\eta)$. 


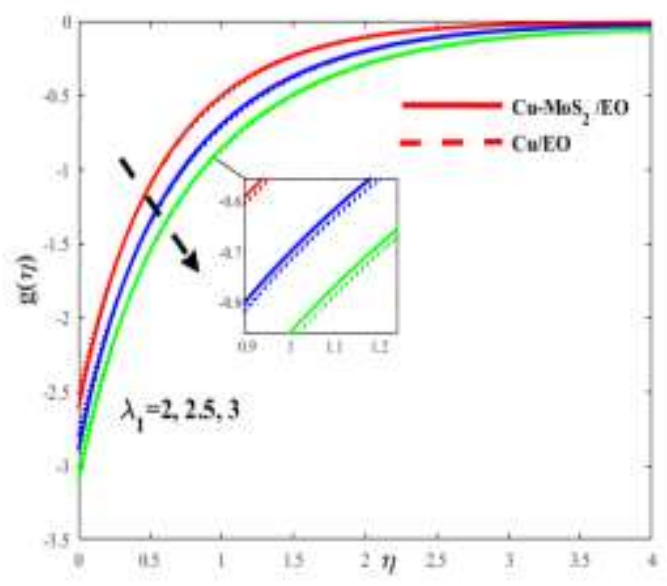

Fig. 17. Effect of $\lambda_{1}$ on $g(\eta)$.

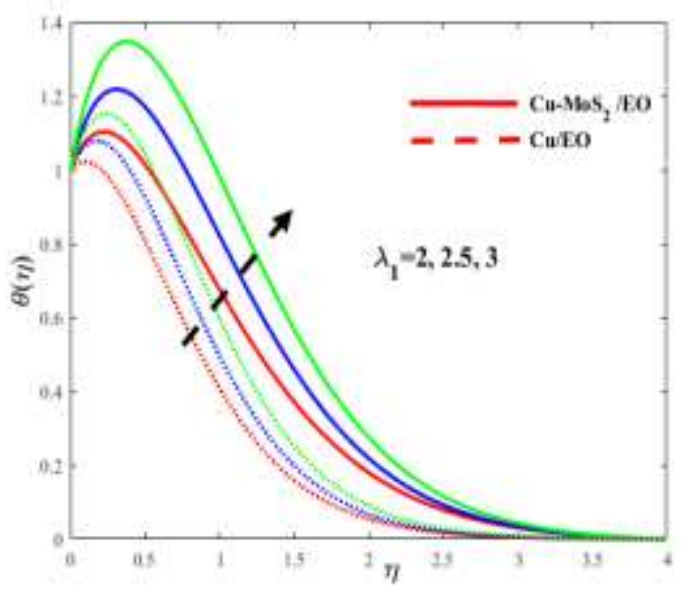

Fig. 18. Effect of $\lambda_{1}$ on $\theta(\eta)$.

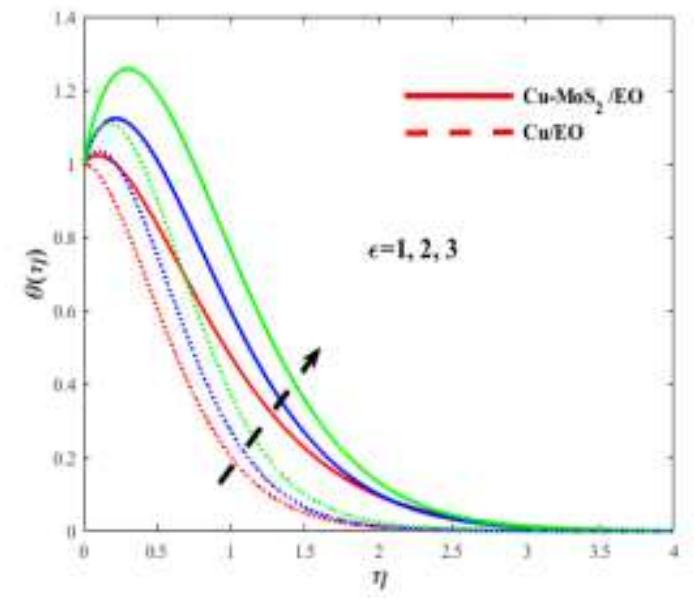

Fig. 19. Effect of $\epsilon$ on $\theta(\eta)$. 


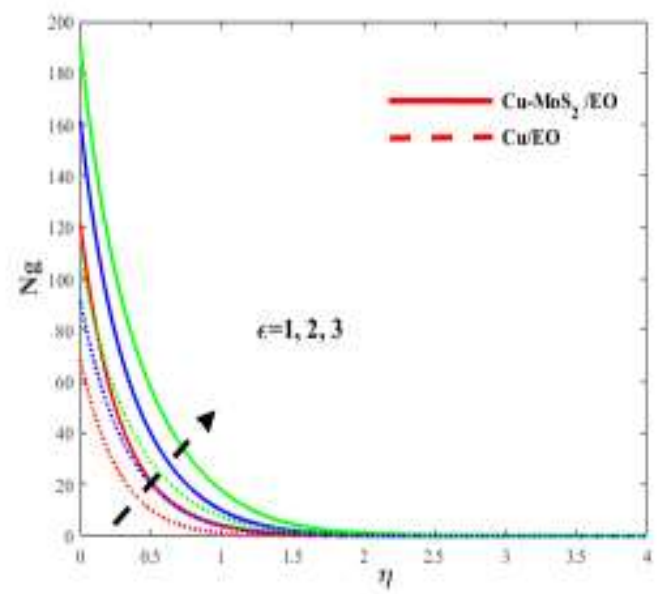

Fig. 20. Effect of $\epsilon$ on $N_{\mathrm{g}}$.

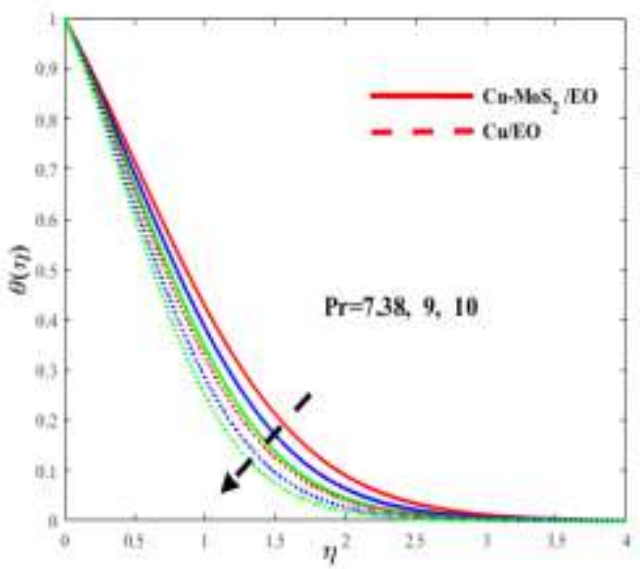

Fig. 21. Effect of $\operatorname{Pr}$ on $\theta(\eta)$.

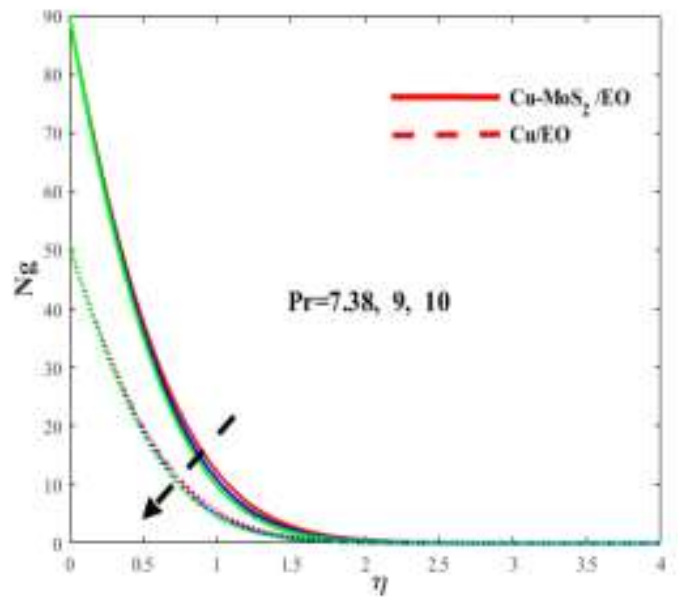

Fig. 22. Effect of $\operatorname{Pr}$ on $N_{\mathrm{g}}$. 


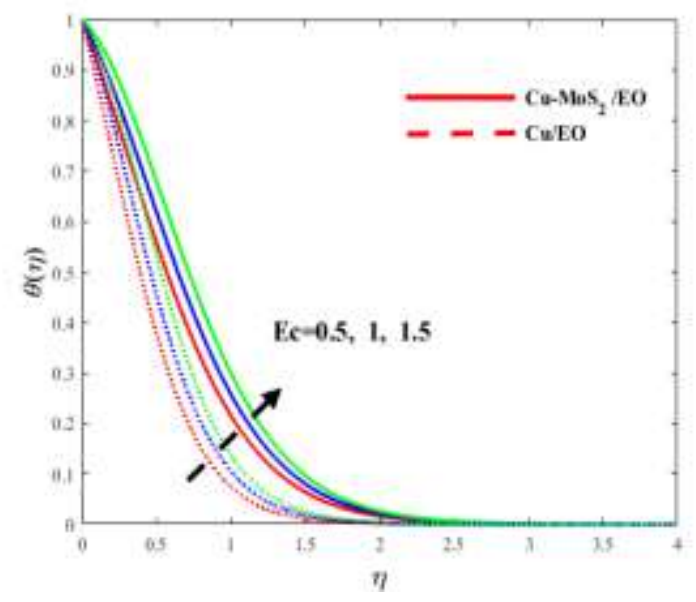

Fig. 23. Change of $E c$ on $\theta(\eta)$.

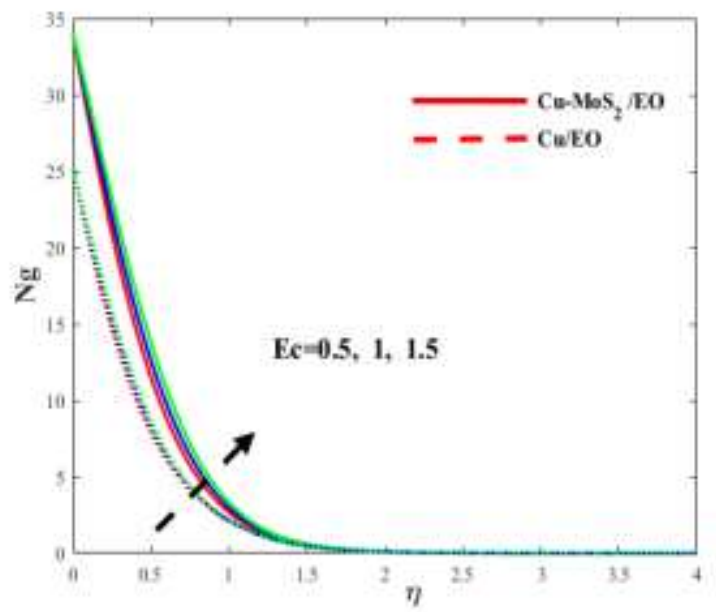

Fig. 24. Change of $E c$ on $N_{\mathrm{g}}$.

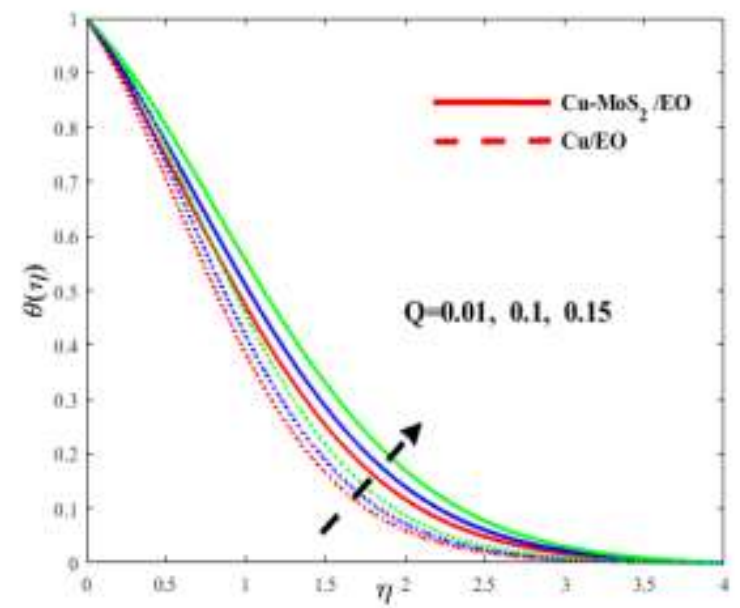

Fig. 25. Change of $Q$ on $\theta(\eta)$. 


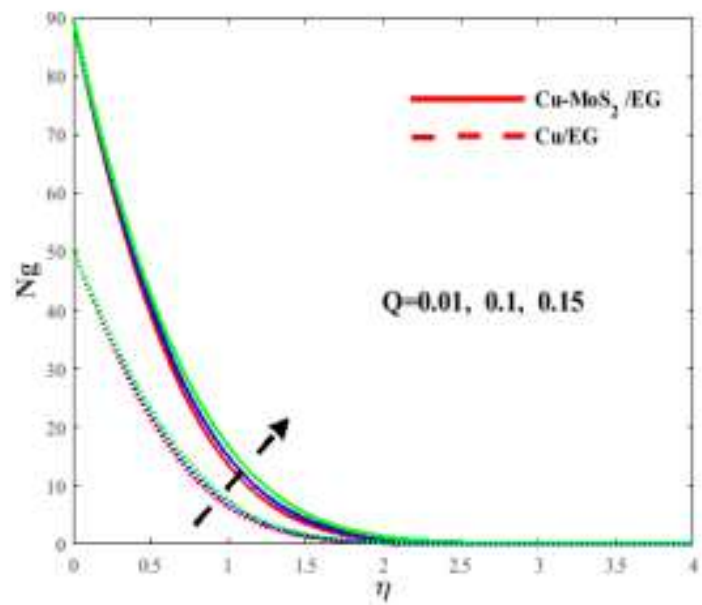

Fig. 26. Change of $Q$ on $N_{\mathrm{g}}$.

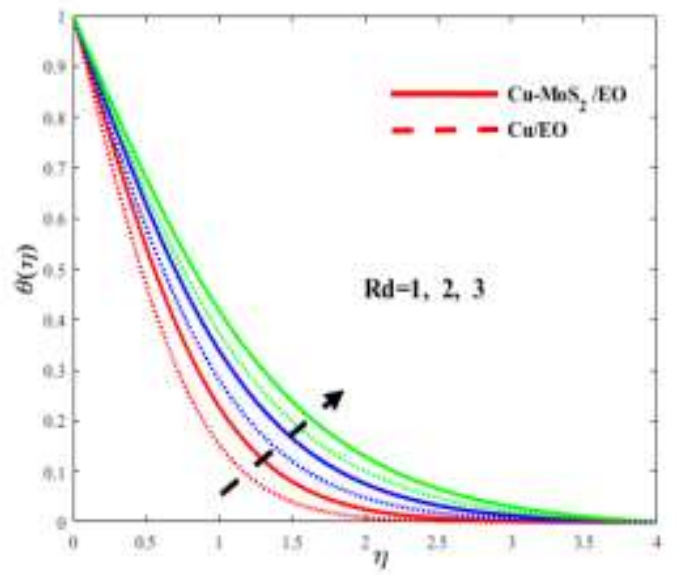

Fig. 27. Change of $R d$ on $\theta(\eta)$.

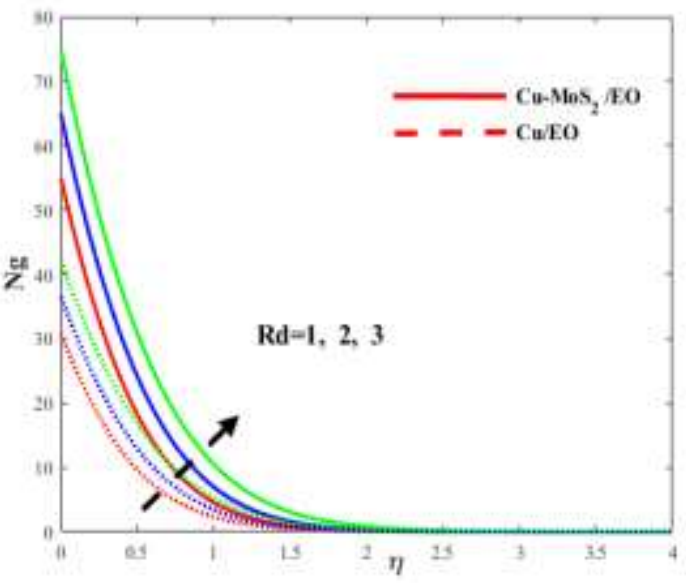

Fig. 28. Change of $R d$ on $N_{\mathrm{g}}$. 


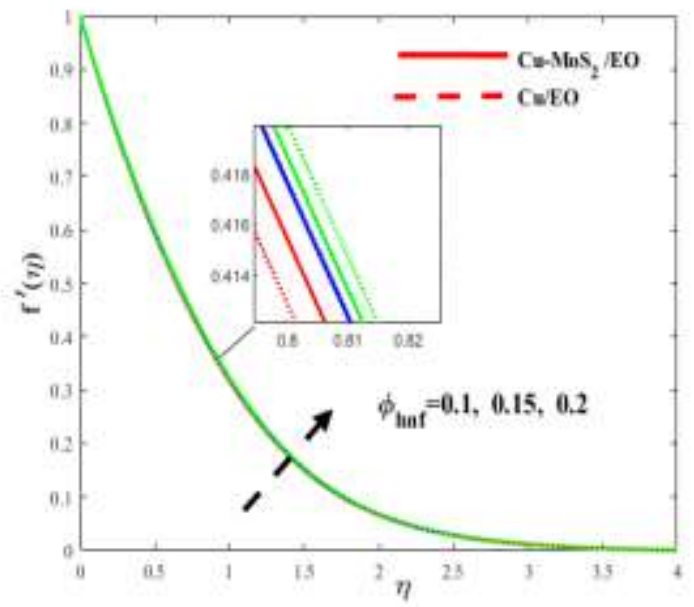

Fig. 29. Change of $\phi_{h n f}$ on $f^{\prime}(\eta)$.

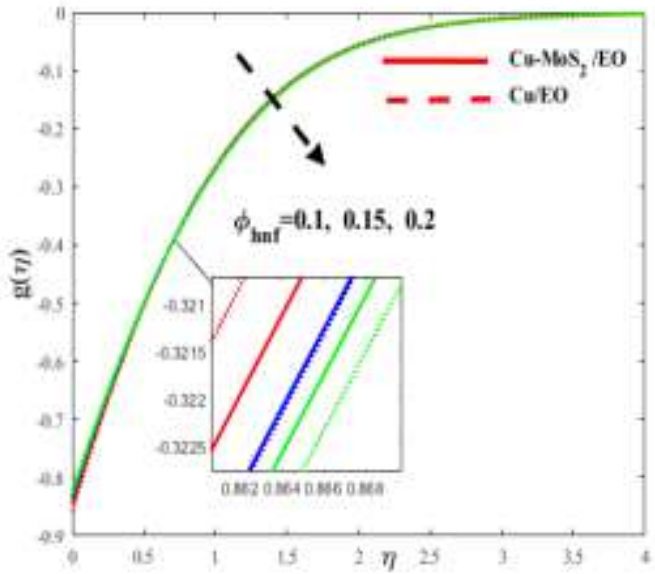

Fig. 30. Change of $\phi_{h n f}$ on $g(\eta)$.

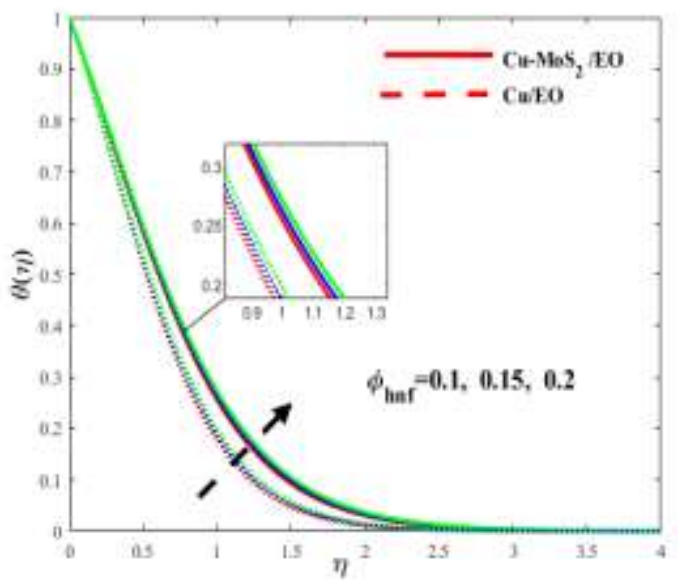

Fig. 31. Change of $\phi_{h n f}$ on $\theta(\eta)$. 


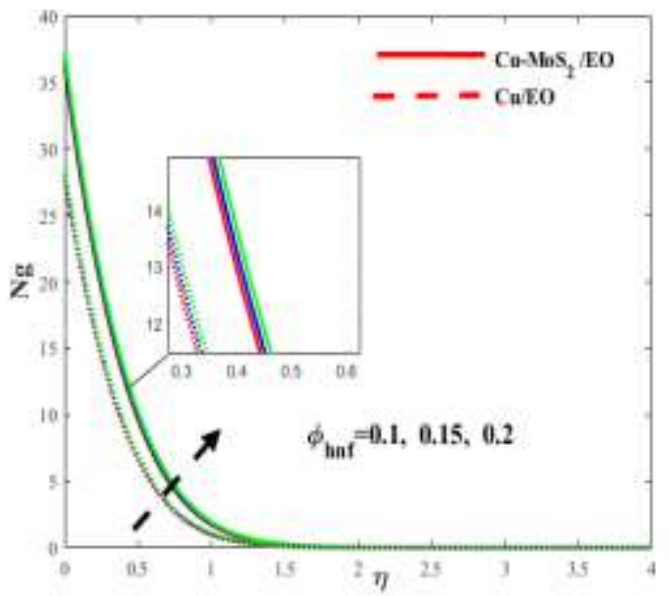

Fig. 32. Change of $\phi_{h n f}$ on $N_{\mathrm{g}}$.

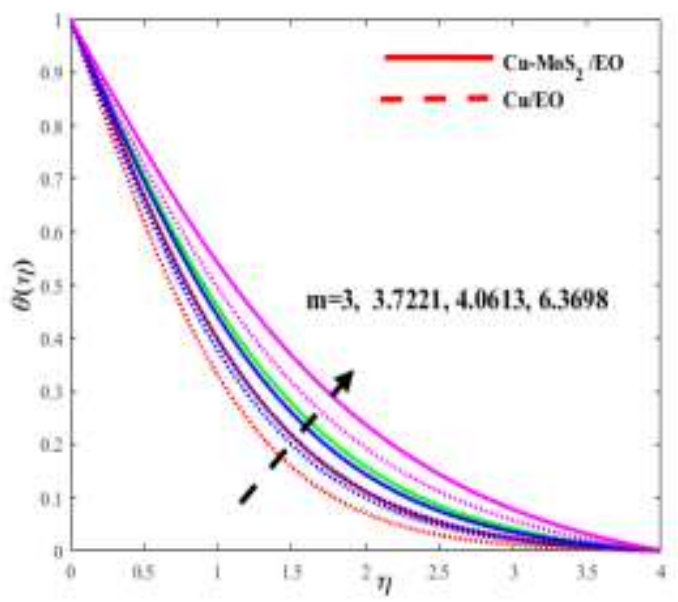

Fig. 33. Change of $m$ on $\theta(\eta)$.

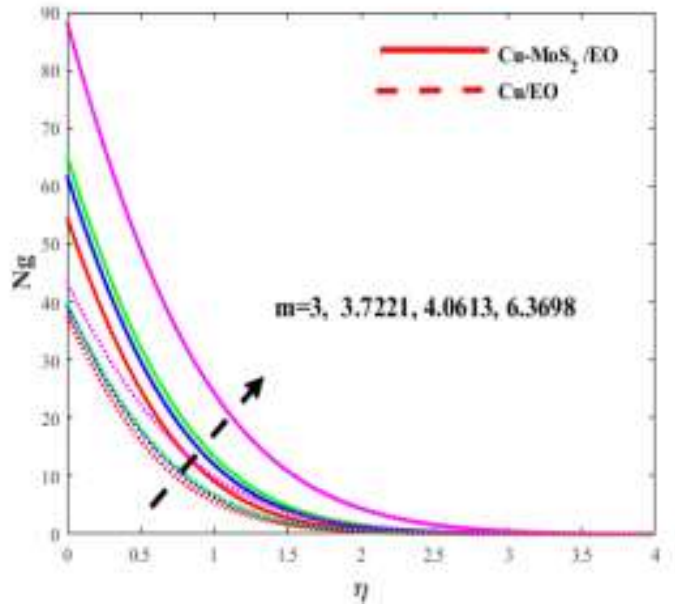

Fig. 34. Effect of $m$ on $N_{\mathrm{g}}$. 
Table 3. Skin friction coefficient against distinct parameters.

\begin{tabular}{|c|c|c|c|c|c|c|c|}
\hline$\epsilon$ & $\operatorname{Pr}$ & $E c$ & $Q$ & $R d$ & $\begin{array}{l}N u_{x} R e_{x}^{\frac{-1}{2}} \\
\mathrm{Cu}-\mathrm{MoS}_{2} / \mathrm{EO}\end{array}$ & $\begin{array}{l}N u_{x} R e_{x}^{\frac{-1}{2}} \\
\mathrm{Cu} / \mathrm{EO}\end{array}$ & $\begin{array}{l}\text { Relative } \% \\
\qquad \frac{N u_{C u-M o S_{2}}-N u_{C u}}{N u_{C u-M o S_{2}}} \%\end{array}$ \\
\hline 0.5 & 7.38 & 0.1 & 0.1 & 0.5 & 2.5116 & 2.2088 & $12.2 \%$ \\
\hline 0.7 & & & & & 2.6271 & 2.3543 & $10.3 \%$ \\
\hline 0.9 & & & & & 2.7211 & 2.4663 & $9.3 \%$ \\
\hline \multirow[t]{13}{*}{0.1} & & & & & 2.8440 & 2.5577 & $10.0 \%$ \\
\hline & 8 & & & & 2.6401 & 2.3184 & $12.1 \%$ \\
\hline & 9 & & & & 2.8363 & 2.4858 & $12.3 \%$ \\
\hline & 10 & & & & 3.0208 & 2.6433 & $12.5 \%$ \\
\hline & & 0.3 & & & 2.4341 & 2.1202 & $12.9 \%$ \\
\hline & & 0.5 & & & 2.3566 & 2.0315 & $13.8 \%$ \\
\hline & & 0.7 & & & 2.2790 & 1.9428 & $14.7 \%$ \\
\hline & & & 0.3 & & 2.4126 & 2.1268 & $11.8 \%$ \\
\hline & & & 0.5 & & 2.5334 & 2.2431 & $11.5 \%$ \\
\hline & & & 0.7 & & 2.5760 & 2.5133 & $2.50 \%$ \\
\hline & & & & 1 & 2.9861 & 2.5968 & $13.1 \%$ \\
\hline & & & & 1.5 & 3.4857 & 2.9987 & $13.4 \%$ \\
\hline & & & & 2 & 3.9255 & 3.3475 & $14.7 \%$ \\
\hline
\end{tabular}


Table 4. Heat and mass transport rates with diverse variables.

\begin{tabular}{|c|c|c|c|c|c|c|c|c|c|c|c|c|c|c|}
\hline$\lambda$ & $\gamma$ & $\lambda_{1}$ & $\epsilon$ & $P r$ & $E c$ & $Q$ & $R d$ & $m$ & $\phi_{h n f}$ & $\phi_{2}$ & $\begin{array}{r}f_{x} R e_{x}^{\frac{1}{2}} \\
\mathrm{Cu}-\mathrm{EO}\end{array}$ & $\begin{array}{c}C f_{x} R e_{x}^{\frac{1}{2}} \\
\mathrm{Cu}-\mathrm{MoS}_{2} / \mathrm{EO}\end{array}$ & $\begin{array}{l}N u_{x} R e_{x}^{\frac{-1}{2}} \\
\mathrm{Cu}-\mathrm{EO}\end{array}$ & $\begin{array}{l}N u_{x} R e_{x}^{\frac{-1}{2}} \\
\mathrm{Cu}-\mathrm{MoS}_{2} / \mathrm{EO}\end{array}$ \\
\hline \multirow[t]{33}{*}{0.5} & 0.5 & 0.1 & 0.5 & 7.38 & 0.1 & 0.1 & 0.5 & 3 & 0.18 & 0.09 & 0.7289 & 0.9525 & 2.2088 & 2.5116 \\
\hline & & & & & & & & & & & 0.8872 & 1.1559 & 2.2367 & 2.5646 \\
\hline & & & & & & & & & & & 0.9957 & 1.2953 & 2.2409 & 2.5725 \\
\hline & 1 & & & & & & & & & & 0.6577 & 0.8584 & 2.1712 & 2.4584 \\
\hline & 1.5 & & & & & & & & & & 0.6403 & 0.8351 & 2.1599 & 2.4429 \\
\hline & 2 & & & & & & & & & & 0.6340 & 0.8265 & 2.1556 & 2.4370 \\
\hline & & 0.3 & & & & & & & & & 0.6023 & 0.7900 & 2.2119 & 2.5100 \\
\hline & & 0.5 & & & & & & & & & 0.2842 & 0.3930 & 2.3387 & 2.6662 \\
\hline & & 0.6 & & & & & & & & & 0.1219 & 0.1902 & 2.4043 & 2.7923 \\
\hline & & & 0.7 & & & & & & & & 0.7289 & 0.9525 & 2.3543 & 2.6271 \\
\hline & & & 0.9 & & & & & & & & 0.7289 & 0.9525 & 2.4663 & 2.7211 \\
\hline & & & 1.1 & & & & & & & & 0.7289 & 0.9525 & 2.5577 & 2.8440 \\
\hline & & & & 8 & & & & & & & 0.7289 & 0.9525 & 2.3184 & 2.6401 \\
\hline & & & & 9 & & & & & & & 0.7289 & 0.9525 & 2.4858 & 2.8363 \\
\hline & & & & 10 & & & & & & & 0.7289 & 0.9525 & 2.6433 & 3.0208 \\
\hline & & & & & 0.3 & & & & & & 0.7289 & 0.9525 & 2.1202 & 2.4341 \\
\hline & & & & & 0.5 & & & & & & 0.7289 & 0.9525 & 2.0315 & 2.3566 \\
\hline & & & & & 0.7 & & & & & & 0.7289 & 0.9525 & 1.9428 & 2.2790 \\
\hline & & & & & & 0.3 & & & & & 0.7289 & 0.9525 & 2.1268 & 2.4126 \\
\hline & & & & & & 0.5 & & & & & 0.7289 & 0.9525 & 2.2431 & 2.5334 \\
\hline & & & & & & 0.7 & & & & & 0.7289 & 0.9525 & 2.5133 & 2.5760 \\
\hline & & & & & & & 1 & & & & 0.7289 & 0.9525 & 2.5968 & 2.9861 \\
\hline & & & & & & & 1.5 & & & & 0.7289 & 0.9525 & 2.9987 & 3.4857 \\
\hline & & & & & & & 2 & & & & 0.7289 & 0.9525 & 3.3475 & 3.9255 \\
\hline & & & & & & & & 3.7221 & & & 0.7289 & 0.9525 & 3.5444 & 4.2633 \\
\hline & & & & & & & & 4.0613 & & & 0.7289 & 0.9525 & 3.6328 & 4.4167 \\
\hline & & & & & & & & 6.3698 & & & 0.7289 & 0.9525 & 4.1753 & 5.3716 \\
\hline & & & & & & & & & 0.09 & & 0.5765 & 0.7405 & 2.6577 & 3.1800 \\
\hline & & & & & & & & & 0.15 & & 0.6692 & 0.8705 & 3.1094 & 3.6694 \\
\hline & & & & & & & & & 0.18 & & 0.7289 & 0.9525 & 3.3475 & 3.9255 \\
\hline & & & & & & & & & & 0.0 & - & 0.7289 & - & 3.3475 \\
\hline & & & & & & & & & & 0.06 & - & 0.8680 & - & 3.7333 \\
\hline & & & & & & & & & & 0.09 & - & 0.9525 & - & 3.9255 \\
\hline
\end{tabular}

\section{Concluding remarks}

The study presents the novel idea regarding the entropy generation analysis and thermal transport analysis of the SACW by considering hybrid RPNF. Different sundry parameters effect in terms of PTSC and SACW have been deliberated extensively and dispalyed in the tabular and 
pictorial procedure. Some salient features of the above mentioned article are summarized underneath

- Heat distrbution phenomenon into SACW improve for the status of diverse parameters $\epsilon$, $R d, Q, m, \phi_{h n f}, \phi$.

- Hybrid nanofluid $\mathrm{Cu}-\mathrm{MoS}_{2} / \mathrm{EO}$ is the well exporter of heat transport in comparing to simple nanoliquid $\mathrm{Cu} / \mathrm{EO}$ for the case of fluid via a PTSC in SACW.

- A magnification in nanoparticles form $m$ enhances heat transfer of fluid past a PTSC.

- Over all system entropy improves for the status of a amplification in $\lambda, Q, R d, \phi_{h n f}, \phi$.

- Thermal radiations $R d$ fall on the surface of PTSC enhances interior energy profiles of SACW.

\section{Nomenclature}

$\begin{array}{llll}R e & \text { Reynold's number } & B r & \text { Brinkman's number } \\ T_{0} & \text { Wall-temperature } & T_{\infty} & \text { Ambient-temperature } \\ \Omega & \text { temperature variation } & \lambda & \text { penetrability parameter } \\ \gamma & \text { nanofluid factor } & \epsilon & \text { variant thermal conductance } \\ E c & \text { Eckert's number } & C f_{x} & \text { frictional force } \\ N u_{x} & \text { Nusselt's number } & R d & \text { radiative parameter } \\ P r & \text { Prandtl's number } & q_{r} & \text { heat radiative flux } \\ Q & \text { heat generation parameter } & \tau_{s} & \text { reference shear stress } \\ \tau & \text { shear stress } & \alpha_{h n f} & \text { hybrid-nanofluid thermal diffusion } \\ \rho_{h n f} & \text { hybrid-nanofluid density } & k_{h n f} & \text { hybrid thermal conductance } \\ C_{p} & \text { specific heat at constant pressure } & \kappa^{*} & \text { absorption coefficient } \\ \sigma^{*} & \text { Stefan-Boltzman constant } & & \end{array}$

\section{Conflict of Interest}

The authors pronounce that there is no conflict of interests.

\section{References}


[1] X. Wang, Y. He, X. Liu, L. Shi, and J. Zhu. Investigation of photothermal heating enabled by plasmonic nanofluids for direct solar steam generation, Solar Energy 157:35-46, 2017.

[2] X. Wang, Y. He, X. Liu, and J. Zhu, Enhanced direct steam generation via a bio-inspired solar heating method using carbon nanotube films, Powder Technology 321:276-285, 2017.

[3] X. Wang, Y. He, X. Liu, and J. Zhu, Solar steam generation through bioinspired interface heating of broadband-absorbing plasmonic membranes, Applied Energy 195:414-425, 2017.

[4] X. Wang, Y. He, X. Liu, and J. Zhu, Direct vapor generation through localized solar heating via carbon-nanotube nanofluid, Energy Conversion and Management 130:176-183, 2016.

[5] A. Noth, R. Siegwart, and W. H. Engel. Design of solar powered airplanes for continuous flight. ETH University, Zurich, Switzerland, 2008.

[6] H. Price, E. Luupfert, D. Kearney, E. Zarza, G. Cohen, and R. Gee, Advances in parabolic trough solar power technology. Journal of Solar Energy Engineering, 109:109-125, 2002.

[7] S.U.S. Choi, Enhancing thermal conductivity of fluids with nanoparticles, Developments and Application of Non-Newtonian Flows 66:99-105, 1995.

[8] H. Masuda, A. Ebata, K. Teramae, Alteration of thermal conductivity and viscosity of liquid by dispersing ultra-fine particles by dispersion of $\mathrm{Al}_{2} \mathrm{O}_{3}, \mathrm{SiO}_{2}$ and $\mathrm{TiO}_{2}$ ultra-fine particles, Netsu Bussei 7:227-233, 1993.

[9] J.A. Eastman, S. Choi, S. Li, W. Yu, L. Thompson, Anomalously increased effective thermal conductivities of ethylene glycol-based nanofluids containing copper nanoparticles, Applied Physics Letters 78(6):718-720, 2001.

[10] M.R. Eid, A. Al-Hossainy, M.S. Zoromba, FEM for blood-based SWCNTs flow through a circular cylinder in a porous medium with electromagnetic radiation, Communications in Theoretical Physics 71(12):1425, 2019.

[11] S. Lahmar, M. Kezzar, M.R. Eid, M.R. Sari, Heat transfer of squeezing unsteady nanofluid flow under the effects of an inclined magnetic field and variable thermal conductivity, Physica A 540:123138, 2020.

[12] M.R. Eid, M.A. Nafe, Thermal conductivity variation and heat generation effects on magneto-hybrid nanofluid flow in a porous medium with slip condition, Waves in Random and Complex Media 1-25, 2020. https://doi.org/10.1080/17455030.2020.1810365

[13] S.A. Adio, M. Sharifpur, J.P. Meyer, Factors affecting the $\mathrm{pH}$ and electrical conductivity of MgO-ethylene glycol nanofluids, Bulletin of Materials Science 38(5):1345-1357, 2015. 
[14] S.N. Shoghl, J. Jamali, M.K. Moraveji, Electrical conductivity, viscosity, and density of different nanofluids: An experimental study, Experimental Thermal and Fluid Science 74:339-346, 2016.

[15] S.F.M. Nor, N. Azis, J. Jasni, M.Z.A. Ab Kadir, R. Yunus, Z. Yaakub, Investigation on the electrical properties of palm oil and coconut oil based $\mathrm{TiO}_{2}$ nanofluids, IEEE Transactions on Dielectrics and Electrical Insulation 24(6):3432-3442, 2017.

[16] S. Jana, A. Salehi-Khojin, W.-H. Zhong, Enhancement of fluid thermal conductivity by the addition of single and hybrid nano-additives, Thermochimica Acta 462(1-2):45-55, 2007.

[17] W. Jamshed, M.R. Eid, N.A.A.M. Nasir, K.S. Nisar, A. Aziz, F. Shahzad, C.A. Saleel, A. Shukla, Thermal examination of renewable solar energy in parabolic trough solar collector utilizing Maxwell nanofluid: A noble case study, Case Studies in Thermal Engineering 27:101258, 2021.

[18] A.F. Al-Hossainy, M.R. Eid, Structure, DFT calculations and heat transfer enhancement in $\left[\mathrm{ZnO} / \mathrm{PG}+\mathrm{H}_{2} \mathrm{O}\right]^{\mathrm{C}}$ hybrid nanofluid flow as a potential solar cell coolant application in a double-tube, Journal of Materials Science: Materials in Electronics 31(18):15243-15257, 2020.

[19] M.R. Eid, A.F. Al-Hossainy, Combined experimental thin film, DFT-TDDFT computational study, flow and heat transfer in $\left[\mathrm{PG}-\mathrm{MoS}_{2} / \mathrm{ZrO}_{2}\right]^{\mathrm{C}}$ hybrid nanofluid, Waves in Random and Complex Media 1-26, 2021. https://doi.org/10.1080/17455030.2021.1873455

[20] A.F. Al-Hossainy, M.R. Eid, Combined experimental thin films, TDDFT-DFT theoretical method, and spin effect on $\left[\mathrm{PEG}-\mathrm{H}_{2} \mathrm{O} / \mathrm{ZrO}_{2}+\mathrm{MgO}\right]^{\mathrm{h}}$ hybrid nanofluid flow with higher chemical rate, Surfaces and Interfaces 23:100971, 2021.

[21] S.O. Giwa, M. Sharifpur, M.H. Ahmadi, S. Sohel Murshed, J.P. Meyer, Experimental investigation on stability, viscosity, and electrical conductivity of water-based hybrid nanofluid of MWCNT- $\mathrm{Fe}_{2} \mathrm{O}_{3}$, Nanomaterials 11(1):136, 2021.

[22] A. Mojiri, R. Taylor, E. Thomsen, and G. Rosengarten, Spectral beam splitting for efficient conversion of solar energy-a review, Renewable and Sustainable Energy Reviews 28:654-663, 2013.

[23] Z. Said and A. Mehmood. Standalone photovoltaic system assessment for major cities of united arab emirates based on simulated results, Journal of Cleaner Production 140:2722-2729, 2017. 
[24] Z. Said, A. A. Alshehhi, and A. Mehmood. Predictions of uae's renewable energy mix in 2030, Renewable Energy 118:779-789, 2018.

[25] E. Bellos, Progress in the design and the applications of linear fresnel re-flectorsea critical review, Thermal Science and Engineering Progress 10:112-137, 2019.

[26] M. Ghodbane, E. Bellos, Z. Said, B. Boumeddane, A. Khechekhouche, M. Sheikholeslami, and Z. M. Ali, Energy, financial, and environmental investigation of a direct steam production power plant driven by linear fresnel solar reflectors, Journal of Solar Energy 143:021008, 2020.

[27] M. Ghodbane, B. Boumeddane, Z. Said, and E. Bellos, A numerical simulation of a linear Fresnel solar reflector directed to produce steam for the power plant, Journal of Cleaner Production 231:494-508, 2019.

[28] G. A. Gonzalez, M. C. Pereira, F. Cuadros, and T. Fartaria. Energy self-sufficiency through hybridization of biogas and photovoltaic solar energy: an application for an Iberian pig slaughterhouse, Journal of Cleaner Production 65:318-323, 2014.

[29] E. Kabir, P. Kumar, S. Kumar, A. A. Adelodun, and K. Kim, Solar energy: potential and future prospects, Renewable and Sustainable Energy Reviews 82:894-900, 2014.

[30] N. Kannan and D. Vakeesan. Solar energy for future world: A review, Renewable and Sustainable Energy Reviews 52:1092-1105, 2016.

[31] C. Luan, Z. Liu, and X. Wang, Divergence and convergence: technology- relatedness evolution in solar energy industry, Scientometrics 97:461-475, 2013.

[32] Y. A. Qandile and M. I. Sabry, Guidelines for the treatment of solar energy topics in the unified science curricula of the Gulf Arab states, Renewable Energy 14:401-414, 1998.

[33] R. Quitzow, J. Huenteler, and H. Asmussen, Development trajectories in China's wind and solar energy industries: how technology-related differences shape the dynamics of industry localization and catching up, Journal of Cleaner Production 158:122-133, 2017.

[34] J. Zhang, Y. Yan, and J. Guan, Scientific relatedness in solar energy: a comparative study between the USA and China, Scientometrics 102:1595-1613, 2015.

[35] A. Sciacovelli, V. Verda, E. Sciubba, Entropy generation analysis as a design tool—a review, Renewable and Sustainable Energy Reviews 43:1167-1181, 2015.

[36] K. Manjunath, S.C. Kaushik, Second law thermodynamic study of heat exchangers: a review, Renewable and Sustainable Energy Reviews 40:348-374, 2014. 
[37] M. Torabi, N. Karimi, G.P. Peterson, S. Yee, Challenges and progress on the modelling of entropy generation in porous media: a review, International Journal of Heat and Mass Transfer 114:31-46, 2017.

[38] O. Mahian, A. Kianifar, C. Kleinstreuer, A. Al-Nimr Moh'd, I. Pop, A.Z. Sahin, S. Wongwises, A review of entropy generation in nanofluid flow, International Journal of Heat and Mass Transfer 65:514-532, 2013.

[39] C. Zhao, S. Zheng, J. Zhang, and Y. Zhang. Exergy and economic analysis of organic rankine cycle hybrid system utilizing biogas and solar energy in rural area of China, International Journal of Green Energy 14:123437, 2017.

[40] W. Jamshed, Numerical investigation of MHD impact on Maxwell nanofluid, International Communications in Heat and Mass Transfer 120:104973, 2021.

[41] M. G. Reddy, M. V. V. N. L. Sudharani, K. G. Kumar, A. J. Chamkha, and G. Lorenzini, Physical aspects of Darcy-Forchheimer ow and dissipative heat transfer of Reiner-Philippof fluid, Journal of Thermal Analysis and Calorimetry 39:11-25, 2019. 